\title{
"En marcha e inmediatamente". Despliegue y desenlace de las tropas de las provincias del sur en la guerra civil chilena de 1891: reclutamiento, problemáticas y consecuencias sociales. \\ "On the move and immediately": Deployment and outcome of the troops of the southern provinces in the Chilean civil war of 1891: recruitment, problems and social consequences.
}

Daniel Catejo Cofré**

\section{RESUMEN}

El siguiente artículo consiste en un análisis referente al despliegue y desenlace de las tropas balmacedistas conformadas en las provincias del sur de Chile durante la guerra civil de 1891, en que se busca distinguir y describir los mecanismos de reclutamiento-forzoso y voluntario-, las resistencias, problemáticas y consecuencias de quienes formaron parte del grueso del ejército de línea en aquel conflicto intra-elite: la tropa, entendida como escalafón institucional a la vez que-en el contexto socioeconómico del último tercio del siglo XIX — como aquellos sujetos que en gran medida pertenecieron al bajo pueblo.

Palabras clave: Tropas, provincias del sur, reclutamiento, bajas militares, consecuencias sociales.

\section{ABSTRACT}

The following article consists of an analysis concerning to the deployment and outcome balmacedist troops formed in the provinces of southern Chile during the civil war of 1891, which seeks to distinguish and describe the types of mechanisms of recruitment-forced and voluntary-the resistances, problems and consequences of those who were part of the thickness of the regular army in that conflict between elites: the troops; This is understood as institutional rankings at the same time as -in the socio-economic context of the last third of the 19th century - those subjects who largely belonged to the lower class folks.

Key words: Troops, southern provinces, recruitment, military casualties, social consequences.

Recibido: mayo 2018

Aceptado: junio 2018

\footnotetext{
"Este artículo se enmarca en el proyecto de investigación VRID 2015.04.042 de la Universidad de Concepción ¿Y de estos muertos quién se encarga?: bases para un memorial de los caídos en la Guerra Civil de 1891; y corresponde a la síntesis de tesis-con idéntico título-para optar al grado de Magíster en Historia por la misma casa de estudios. Cabe destacar que en el proceso de dicho proyecto, varias personas aportaron en el tratamiento de fuentes documentales. Entre ellas Pamela Fernandez Navas, en la revisión y transcripción de las listas de revista de comisario del Archivo Histórico del Ejército de Chile, labor cuya recopilación digital fue realizada previamente en el mismo lugar por Constanza Abásolo Gonzalez y Claudio Peña Bravo. Finalmente fue gravitante también la revisión y catalogación de fuentes bibliográficas realizadas por Isaías Santos Ruiz.

${ }^{* *}$ Licenciado en Historia y Magíster en Historia (C), Universidad de Concepción. Correo electrónico: danielcatejo@udec.cl
} 


\section{Introducción}

La motivación de esta indagación histórica surge a partir de una reflexión acerca del tratamiento historiográfico de los diversos quiebres sociopolíticos que ha enfrentado Chile a lo largo de su vida republicana. Particularmente, llama la atención cómo se han abordado los efectos de las guerras decimonónicas y la dictadura militar de 1973 en el interregno entre la historia lejana e historia reciente, respectivamente. En el segundo caso se ha atendido con mayor profundidad las dimensiones sociales de las consecuencias del proceso, particularmente en el rescate y reparación memorial de las víctimas de la dictadura. En cambio, al observar los estudios relativos a los efectos sociales que tuvieron las diversas guerras -internas y externasocurridas durante el siglo XIX no han recibido la misma atención. La Guerra contra la Confederación Perú-boliviana (1836 - 1839) y la Guerra del Pacífico (1879 - 1883) en la historiografía y en el acervo común, instalaron una visión triunfalista acorde a un sentimiento de unidad nacional. En cambio, la Guerra Civil de 1891 tuvo un impacto desmoralizante, tanto para las instituciones en disputa, como también para la sociedad, especialmente en aquellos grupos que fueron impelidos a alistarse y enfrentarse entre sí. El impacto social de esta guerra es una deuda pendiente en la historiografía, especialmente cuando se trata de dilucidar lo ocurrido con los miles de individuos que participaron, murieron y que resultaron heridos, además de aquellos flagelos sociales como la violencia, el bandolerismo, el alcoholismo, las enfermedades y desamparo institucional en la época posterior al conflicto.

Conforme a lo anterior, este estudio busca entregar una representación historiográfica social del paisaje distante ${ }^{1}$ que fue dicha guerra civil chilena, específicamente de conformación, problemáticas y consecuencias de las tropas reclutadas en las provincias del sur de Chile que conformaron la División de Concepción con cerca de diez mil hombres. La hipótesis que se plantea es que la división balmacedista del sur se conformó a partir del enganche voluntario y forzoso de la población perteneciente a los sectores populares de las provincias de Nuble, Concepción, Arauco, Biobío, Malleco, Cautín, Valdivia, Llanquihue y Chiloé. Las bajas más recurrentes en la tropa de este cuerpo militar durante el período de acuartelamiento fueron las enfermedades y las deserciones. En cuanto a las batallas del conflicto, sólo unas pocas unidades del sur participaron en Pozo Almonte y Concón, mientras que en Placilla logró entrar en acción gran parte del contingente. Finalmente, el desenlace del conflicto para las provincias del sur, además de las pérdidas humanas y gran cantidad de heridos, fueron el desarrollo de bandolerismo y un extenso debate por las recompensas militares.

\footnotetext{
${ }^{1}$ Gaddis, J. 2002. El paisaje de la historia. Cómo los historiadores representan el pasado, Barcelona, Editorial Anagrama, p. 19.
} 


\section{Una propuesta de historia social y regional de la guerra civil de 1891 en el sur de Chile.}

Para abordar la Guerra Civil de 1891, como objeto de análisis, fue necesario adoptar y hacer converger algunos elementos teórico-metodológicos de la Sociología de la Guerra, la Historia Social y la Historia Regional.

Desde la denominada sociología de la guerra se asume el valor científico de la guerra que plantea Flabián Nievas, consistente en que "el fenómeno abordado es la actividad social por la cual unos grupos humanos tratan, por medio del uso sistemático y potencialmente racional de la violencia, de doblegar la voluntad de otros grupos humanos, para lo cual deben exterminarlos en parte." ${ }^{2}$ En este sentido, el objeto de este estudio se orienta hacia la observación de aquella dinámica de la guerra en un grupo social concreto, en la cual, además, se asume dicha experiencia histórica desde un punto de vista individual en tanto acción racional-a la manera weberiana - como una orientación subjetivamente comprensible de la propia conducta de aquellos sujetos que se enfrentan en un conflicto bélico, ya sea de acuerdo a fines, a valores, emociones o producto de la tradición ${ }^{3}$.

Respecto con la Nueva Historia Social, se ha considerado la visión teórica de Gabriel Salazar, la cual aborda fundamentalmente la historicidad de los sujetos populares en Chile. ${ }^{4}$ Este autor plantea el desarrollo histórico de las relaciones sociales entre la elite y el bajo pueblo, que acorde al propósito de esta investigación, tendría como resultado una impronta social "desde abajo" en un conflicto marcadamente institucional llevado a cabo "desde arriba". Además, desde esta perspectiva, se asume que los soldados de línea pertenecieron a los sectores populares y que al ser movilizados a través de la Guardia Nacional se transformaron en un "ciudadano $\operatorname{armado}{ }^{5}$ que formó parte de la denominada "tropa".

Por otro lado, desde el prisma regional, en este análisis es necesario integrar los contextos locales y globales dando especial énfasis al acontecer social en y entre las provincias en las cuales fueron movilizados los brazos humanos para la guerra. Se trata de una perspectiva territorial y demográfica que permite figurar, además, la diversidad de identidades que se componen e interactúan en un espacio y acontecimiento. En palabras de Manuel Miño, se debería asumir el corte regional no como "simplemente algo que está 'ahí' sino un espacio

\footnotetext{
2 Nievas, F. 2009. "Sociología de la Guerra", Redes.com: Revista de estudios para el desarrollo social de la Comunicación. ISSN 1696-2079, №5, p. 28.

${ }^{3}$ Weber, M. 2001. La ética protestante y el espíritu del capitalismo, Barcelona, Ediciones Península.

${ }^{4}$ Salazar, G. 2015. Labradores, Peones y Proletarios. Formación y crisis de la sociedad popular chilena del siglo XIX. Santiago de Chile, LOM ediciones (decimoséptima reimpresión).

${ }^{5}$ Pinto, J. \& Valdivia, V. 2009. ¿Chilenos todos? La construcción social de la nación (1810-1840), Santiago de Chile, LOM ediciones, p.81.
} 
privilegiado de investigación que se construye tanto por el observador como por los sujetos que viven en ese espacio." ${ }^{6}$

Conforme a lo anterior, esta investigación comprende como partes fundamentales del análisis, el despliegue y desenlace de los individuos de tropa en las provincias del sur de Chile. En consecuencia, en dichos procesos subyacen conceptos fundamentales que nos permitirán entender global y particularmente las dimensiones sociales del fenómeno que significó este enfrentamiento bélico. Primero, el concepto de tropa se entiende bajo una dimensión social que históricamente ha estado asociada a la mitificada imagen de los "rotos del bajo pueblo"7 En segundo lugar, el enganche consiste en dos modalidades de reclutamiento; uno forzoso que es propio de un sistema tradicional ${ }^{8}$, en el cual obligatoria y violentamente se doblega la voluntad de un individuo para formar parte de una lucha armada; y un reclutamiento voluntario, que básicamente consistía en el pago de primas de dinero. En suma, ambos mecanismos son relevantes a la hora de aclarar el proceso de despliegue de las tropas, ya que, pese que también se tratan de conceptos propios de la jerga militar, también se pueden operacionalizar del modo en que lo plantea Thompson: "el reclutamiento puede ser un indicador económico, sociocultural y, aún quizás, político, un indicador que refleje las fluctuaciones de las condiciones de la vida y del trabajo, las tradiciones y comportamientos mentales de unas determinadas capas sociales y las posturas de adherencia o de rechazo a las políticas y empresas dinásticas, religiosas y nacionales" ${ }^{9}$.

Por otro lado, en lo que concierne al proceso de acuartelamiento es preciso considerar la serie problemáticas que afectaron a la tropa que figuran en las fuentes militares como bajas: licenciados, desertores, enfermos, expulsados, presos y muertos. Bajo la óptica social, estas problemáticas son el reflejo de las resistencias y la falta de aptitud de los sujetos que conformaron la tropa reclutada para guerra. Por último, queda aclarar que el término provincias del sur opera en este estudio como un corte político administrativo propio del siglo XIX, el cual permite sistematizar localizadamente el análisis de la estructura social de la población movilizada.

Conforme a lo anterior, la metodología empleada en este trabajo cumple un propósito de carácter descriptivo, explicativo y comparativo en tanto enfoque sociológico, histórico y regional, respectivamente. Para lograrlo, se ha adoptado un método de análisis cuantitativo,

\footnotetext{
${ }^{6}$ Miño, M. 2002. “¿Existe la Historia Regional?”, Historia Mexicana, abril-junio, vol. LI, N004, México D.F. El Colegio de México, pp. 867-897, p. 871.

${ }^{7}$ Salazar, G. \& Pinto, J. 2002. Historia Contemporánea de Chile IV: Hombría y Feminidad, Santiago de Chile LOM ediciones, p. 18.

${ }^{8}$ Los autores anteriormente citados coinciden en esta dimensión tradicional del reclutamiento forzoso con León, L. 2011. Ni patriotas ni realistas. El bajo pueblo durante la Independencia de Chile 1810-1822, Santiago de Chile, Ediciones de la Dirección de Bibliotecas. Archivos y Museos.

${ }^{9}$ Dicho perfil del soldado en clave económica y sociocultural es mencionado por Thompson I.A.A. 2003. "El soldado del Imperio. Una aproximación al perfil del Recluta español del siglo de oro." Manuscrits 21, pp. 17-38.
} 
por lo que fue necesario valerse de cuadros estadísticos y gráficos construidos a partir de la información recopilada. La unidad de análisis será, esencialmente, las tropas balmacedistas de las provincias del sur y todos los fenómenos involucrados en los procesos despliegue y desenlace del conflicto.

\section{La historiografía sobre la guerra civil chilena de 1891 . Desde lo institucional a lo social y regional.}

La historiografía chilena sobre la Guerra Civil de 1891 ha abordado este episodio desde una perspectiva eminentemente político-institucional, en especial, la historiografía conservadora y marxista $^{10}$, en las obras de extranjeros ${ }^{11}$ y algunos estudios generales y colaborativos $^{12}$. Alejandro San Francisco ha dado un vuelco al análisis político institucional de la guerra civil de 1891 al proponer la necesidad de estudiarla desde un punto de vista "pluricausal". Este autor también ha logrado dar énfasis en sus estudios al carácter de la politización que tuvieron las Fuerzas Armadas en dicho conflicto ${ }^{13}$.

\footnotetext{
${ }^{10}$ En la corriente conservadora, en su Historia de Chile, Encina, otorga un carácter ideológico activo a los sectores más bajos de la sociedad, en especial, a los campesinos de la zona central de Chile que fueron arrastrados obligatoriamente al conflicto. Sin embargo, este realiza estas aseveraciones a partir de "noticias acerca de tales acontecimientos" y no precisamente de fuentes que lo evidencien; ver Encina, F. A. 1952. Historia de Chile. Desde la prehistoria hasta 1891, Tomo XX, Santiago, Editorial Nascimento. Pp. 193-194. Mientras tanto, los historiadores marxistas clásicos de mediados del siglo XX, especialmente, Hernán Ramírez Necochea y Luis Vitale abordan la guerra civil e 1891 desde la óptica dialéctica de la dominación e influencia del capital inglés en la política chilena de ese periodo, concordando además en que la participación popular en el conflicto tuvo una suerte de adhesión "pasiva" a la causa balmacedista. Por su parte, en esta misma Julio Cesar Jobet señala que el "pueblo", la mayoría de la nación se mantuvo indiferente a la contienda, pero termina por asumir que "los ejércitos de uno y otro bando se formaron con la carne de cañón de siempre, la plebe, el roto". Ver: Ramírez Necochea, H. 2007. Obras escogidas. Balmaceda y la contrarrevolución de 1891. Historia del Movimiento Obrero en Chile. (1958) Volumen I, Santiago de Chile, LOM ediciones; Vitale, L. 1992. Interpretación marxista de la historia de Chile. Tomo V, Santiago de Chile, Ediciones Cela, Rucaray; y Jobet, J. C. 1955. Ensayo crítico del desarrollo económico-social de Chile, Santiago de Chile, Editorial Universitaria.

${ }^{11}$ En esta categoría son importantes las obras realizadas por Brian Loveman y Elizabeth Lira, Simon Collier y Willian Sater. Los dos primeros autores indican el fenómeno de amnistías políticas y su relevancia en la reconstrucción de la memoria social e histórica entre los siglos XIX y XX. Por su parte, en la Historia de Chile 1804-1994 de Simon Collier y William Sater, se abordan particularmente los costos humanos del conflicto, aunque sus cifras resultan ser aproximadas. Ver: Loveman, B. \& Lira, E. 1999. Las suaves cenizas del olvido. Vía chilena de reconciliación política 1814-1932, Tomo I, Santiago de Chile, LOM ediciones; y Collier, S. \& Sater, W. 1998. Historia de Chile, 1808-1994, Cambridge, U.K.: Cambridge University Press.

${ }^{12}$ A principios de la década de 1990, con motivo de cumplirse el centenario de la Guerra Civil de 1891, se editó una investigación colectiva dirigida por Luis Ortega llamada La guerra civil de 1891: 100 años hoy (1991). Aquí se agrupan valiosos estudios sobre la crisis de 1891, desde un punto de vista tanto político como social de historiadores como Alfredo Jocelyn- Holt, Gabriel Salazar, Rafael Sagredo y Julio Pinto. Ver: Ortega, L.(editor). 1991. La guerra civil de 1891: 100 años hoy. Santiago, Universidad de Santiago de Chile.

13 San Francisco, A. 2006. "Historiografía y nuevas perspectivas sobre la Guerra Civil chilena de 1891", BICENTENARIO, Revista de Historia de Chile y América, Vol. 5, n¹, Santiago de Chile, Centro de Estudios Bicentenario, pp. 85-125.
} 
No obstante, al observar el desarrollo de la historiografía chilena sobre los aspectos sociales de las guerras que desataron en Chile durante el siglo XIX, se puede constatar que en esta materia han predominado los estudios relativos fundamentalmente a la Guerra de la Independencia y a la Guerra del Pacífico. En la primera de ellas, es sustantivo el trabajo de Leonardo León, Ni patriotas ni realistas. El bajo pueblo durante la Independencia de Chile 18101822, en el cual problematiza los mecanismos de reclutamiento y las consecuencias del conflicto, aseverando al respecto que "la resistencia del bajo pueblo a participar en las campañas militares obligó al reclutamiento forzado de labriegos, peones y jornaleros". ${ }^{14}$ En síntesis, la categorización social que atribuye este autor a los individuos que lucharon como soldados de pie es explicita en este amplio estudio. Por otro lado, en las investigaciones acerca de la Guerra del Pacífico, son más notorios los temas de índole social. Los efectos negativos que tuvo la guerra en los soldados y en la población civil son abordados en mayor medida acerca de la Guerra del Pacífico por David Home, Carlos Méndez Notari, Carlos Donoso y Juan Ricardo Couyoumdjian ${ }^{15}$. En esta misma línea de investigación, es relevante la Historia Social del Ejército de Chile. Ejército, sociedad y familia en los siglos XVIII y XIX (1993), de Sergio Vergara Quiroz, específicamente, al análisis que realiza sobre el ejército como institución política y social en Chile, estableciendo que dentro de la composición social del ejército en Chile "la tropa se reclutaba de preferencia entre los marginales y delincuentes del mundo urbano, más el enganche forzado de los hombres humildes, mal entretenidos o vagabundos." ${ }^{16}$ Por último, desde el campo de la Historia Militar también es posible apreciar algunas claves sociológicas en el trabajo realizado por Sergio Rodriguez Rautcher sobre la Problemática del soldado durante la Guerra del Pacífico (1986). ${ }^{17}$ Si bien este autor es reticente al manifestar alguna comprensión de las circunstancias sociales de la guerra, señalando que aquellas deben abordarse necesariamente desde un punto de vista tradicional, nos entrega un panorama estadístico detallado sobre las deserciones y licenciamientos del ejército de línea y la Guardia Nacional en la época de la Guerra del Pacífico. Este estudio, al igual que el de Sergio Vergara, contiene una amplia y fundamental documentación militar lo cual hace viable un análisis sociológico, aunque rotundamente sesgado por la perspectiva castrense.

\footnotetext{
${ }^{14}$ León, L. 2011. Ni patriotas ni realistas. El bajo pueblo durante la Independencia de Chile 1810-1822,p. 177.

${ }^{15}$ Home Valenzuela, D. 2006. Los huérfanos de la Guerra del Pacífico: El "Asilo de la Patria", 1879-1885. Santiago, Colección Sociedad y Cultura, Centro de Investigación Diego Barros Arana, LOM Ediciones; Méndez Notari, C. 2009. Héroes del Silencio. Los Veteranos de la Guerra del Pacífico (1884-1924), Santiago, Ediciones Centro de Estudios Bicentenario; Donoso, C. \& Couyoumdjian, J. R. 2005. "De soldado orgulloso a veterano indigente. La Guerra del Pacífico. En Sagredo, R. \& Gazmuri, C. 2005. Historia de la vida privada en Chile. El Chile Moderno de 1840 a 1925. Tomo 2, Santiago de Chile, Aguilar Chilena de Ediciones S.A.

${ }^{16}$ Vergara Quiroz, S. 1993. Historia Social del Ejército de Chile. Vol. I Ejército, sociedad y familia en los siglos XVIII y XIX. Santiago de Chile, Universidad de Chile, Dirección general Académica Estudiantil, p. 178.

17 Rodriguez Rautcher, S, 1986. Problemática del soldado durante la Guerra del Pacífico, Santiago, Colección Biblioteca Militar LXX-1, Edimpres Ltda, p. 5.
} 
Por otra parte, es valioso para el enfoque de este estudio uno de los trabajos más recientes sobre la guerra civil chilena de 1891 que, en conjunto realizan Rodrigo Mayorga (editor), Pablo Neut, Cecilia Morán, Claudio Vivanco, Mariano Larraín y María Soledad del Villar: Lejos del ruido de las balas. La guerra civil chilena de 1891 (2008) ${ }^{18}$. En esta investigación se abordan nuevos aspectos de la guerra civil relativos al mundo popular, a la sublevación, traición y deserción militar, la vida cotidiana de los soldados del ejército constitucional, el frente externo de la guerra, el liderazgo político y la llegada a la presidencia de Jorge Montt, y la visión heroica de Balmaceda. Desde estas nuevas miradas, es preciso poner en relieve el trabajo de Pablo Neut y Cecilia Morán. El primer autor, propone que la participación popular estuvo centrada en la batalla por la legitimidad del conflicto entre los bandos en disputa por persuadir a los sectores populares del país para que se reclutaran voluntariamente; mientras que la segunda autora aborda la sublevación, traición y deserción militar que se desarrolló durante el conflicto en la facción balmacedista, centrando su análisis, bajo un enfoque regional, en el norte chico del país. $^{19}$

Entre los estudios sobre la Guerra Civil de 1891 enfocados en el sur del país, habría que mencionar la obra realizada por Jorge Pinto sobre ciertos aspectos sociales manifestados antes y después de los hechos de 1891 en lo que se conoce como frontera del sur de Chile ${ }^{20}$. En este sentido resulta novedoso el análisis realizado sobre la problemática del bandolerismo desarrollado hacia fines del siglo XIX en esta zona, fenómeno acrecentado en los años posteriores a la guerra civil del 91 y que en este estudio es considerado como una de las consecuencias de largo plazo en la zona sur de Chile. Además, Pinto es categórico al señalar que "el tiempo de Balmaceda, fue un tiempo de muerte" ${ }^{21}$, afirmación que tiene directa relación con los brotes de violencia en la frontera producto de la ocupación del ejército de Chile. Por otro lado, quien se acerca aún más a la propuesta investigativa que aquí se plantea es José

\footnotetext{
${ }^{18}$ Mayorga, R.; Neut, P. [Et. al]. 2008. Lejos del ruido de las balas: la guerra civil chilena de 1891, Santiago de Chile, Centro de Estudios Bicentenarios.

${ }^{19}$ Neut, P. 2008. "La otra oposición. El mundo popular frente a la causa balmacedista durante la guerra civil de 1891." En Ibid, pp. 44-96; Y Morán, C. 2008. "Sublevación, Traición y Deserción militar en la Guerra Civil de 1891. El caso del ejército balmacedista. En Mayorga, R.; Neut, P. [Et. al]. 2008. Lejos del ruido de las balas: la guerra civil chilena de 1891, Óp. Cit. Pp. 97-135. Dentro de los trabajos en conjuntos, hay que destacar también la obra de Salinas, M.; Cornejo, T. \& Saldaña, C. 2005. ¿Quiénes fueron los vencedores? Elite, pueblo y prensa humorística de la Guerra Civil de 1891, Santiago, LOM y Centro de Investigaciones Diego Barros Arana; quienes, basándose en la prensa humorística del período, grafican el quiebre social tanto de la Élite política como del Pueblo chileno durante la guerra civil de 1891. Este estudio, permite acercarse a las visiones positivas y negativas del gobierno de Balmaceda a partir de un significativo respaldo documental basado en la prensa satírica de la época.

${ }^{20}$ Pinto Rodríguez, J. 2015. Conflictos fronterizos en la Araucanía, siglos XIX y XX. Temuco, Ediciones Universidad de la Frontera.

${ }^{21}$ Ibid. P. 103. Específicamente, el autor dedica un capítulo completo a la descripción de los hechos de violencia en la frontera chilena en los tiempos de Balmaceda, haciendo énfasis en el bandolerismo que se produjo a partir de los diversos desajustes vividos en la región desde mediados del siglo XIX. Ver Ibid. pp. 67-105.
} 
Alejandro Pizarro Soto, con su obra Lebu. De la Leufumapu a su Centenario 1540-1962 (1962) ${ }^{22}$. Este estudio es clave para comprender cómo fue el proceso de conformación de las tropas y sus consecuencias sociales a nivel local y provincial. El autor dedica un extenso apartado a la Revolución de 1891, en el que pone en relieve la ocupación de Lebu por el "Esmeralda" y los mecanismos de reclutamiento forzoso llevados a cabo por los balmacedistas en la provincia de Arauco. En dicho lugar este autor hace referencia a la conformación del Regimiento Arauco, el Constitución $n^{\circ} 1$ y al despliegue de las brigadas cívicas. A su vez, este autor logra identificar las principales consecuencias de la guerra civil en la comuna de Lebu en el período al que denomina de una "larga convalecencia" - desde 1892 hasta 1906-momento en que surge una lucha reivindicativa de las masas trabajadoras y el desarrollo de un bandolerismo sin control en la provincia, fenómeno que afirma se vio acentuado una vez finalizado el conflicto en cuestión.

Finalmente, desde la perspectiva popular de la guerra civil, es relevante el trabajo historiográfico realizado por Fernando Venegas titulado "Los sectores populares en la Guerra Civil de 1891: consecuencias de su desenlace en Placilla" ${ }^{23}$. Aquí, el autor pone de manifiesto el problema de la violencia en la sociedad popular de fines del siglo XIX, donde es relevante detenerse en el despliegue de violencia interclasista fomentado por la oligarquía, el bandolerismo desarrollado posteriormente a la guerra, la situación de los soldados derrotados que huyeron al campo de batalla hacia los espacios rurales; la falta de identificación de los cuerpos de los muertos y la inexistencia de una lista oficial de las víctimas. ${ }^{24}$ Estas conclusiones, junto con las establecidas por Pizarro Soto, son las principales referencias historiográficas para esta investigación, esencialmente por su perspectiva regional y por dar énfasis en la participación y consecuencias sociales de los sectores populares en la guerra civil de 1891.

\section{Las dimensiones territoriales y socioeconómicas de las provincias del sur de Chile desde 1860 hasta 1891.}

En el ámbito económico, las provincias del sur de Chile desde el último cuarto del siglo XIX fueron zonas eminentemente agrícolas, portuarias, carboníferas y textiles. Ante el escenario bélico de 1891, estas provincias se transformaron en espacios estratégicos para abastecimiento de manufactura, alimentos, combustible y dotación de personas del ejército presidencialista. En concreto, dentro de los márgenes político-administrativos del Chile decimonónico, se trata de las provincias de Ñuble, Concepción, Arauco, Bío-Bío, Malleco, Cautín, Valdivia, Llanquihue y Chiloé. Esta delimitación territorial no es meramente deliberada, pues, el motivo principal,

\footnotetext{
${ }^{22}$ Pizarro Soto, J. A. 1991. Lebu. De la Leufumapu a su centenario 1540-1962 Santiago, Editorial Ñielol S.A.

${ }^{23}$ Venegas, F. 2013. "Los sectores populares en la Guerra Civil de 1891: consecuencias de su desenlace en Placilla", en Ávalos H; Saunier, A; Delgado, A. \& Venegas, F. 2013. Bosque de La China: testimonio de un pasado sangriento. Batalla de Placilla - 1891. Consejo Nacional de la Cultura y las Artes. Valparaíso, Proyecto FONDART N64376, Convocatoria 2008.

${ }^{24}$ Ibid, pp. 76-79.
} 
como se verá más adelante, se debe a la correlación que hubo en aquél entonces entre la organización militar de las fuerzas de tierra y los lugares de reclutamiento. Gran parte de las brigadas cívicas movilizadas en las provincias señaladas convergieron, finalmente, en la ciudad de Concepción, donde conformaron la 7ạ $-y$ posteriormente 4a -División Concepción del ejército presidencial, unidad militar que alistó cerca de 10.000 personas para el ejército balmacedista.

Chile, por aquél entonces, se estaba insertando en la economía mundial, donde la expansión hacia territorios no explotados del sur era vital para lograr una modernización bajo las consignas decimonónicas de orden y progreso, sobre las cuales se justificó y consolidó el sistema político el país al menos hasta $1925^{25}$. Junto al aumento de la población urbana a nivel nacional, hubo una colonización en los territorios de la frontera, que fue tomando distintos matices desde mediados del siglo XIX en adelante. Según Jorge Pinto, la Araucanía se incorporó económicamente al país forzada por la crisis económica de 1857, que "obligó a los grupos dirigentes de Santiago a buscar nuevas tierras y nuevos mercados para sostener la economía exportadora que se consolidó después de la Independencia" ${ }^{26}$, agregando que este proceso de expansión se extendió hasta 1930, debido a las "condiciones generadas por la ocupación del territorio por parte del Estado" ${ }^{27}$, lo cual permitió que esta zona atrajera a colonos extranjeros y nacionales.

De acuerdo con el orden económico tradicional, durante el siglo XIX, en las provincias del sur no se observa un intento serio por parte de la clase terrateniente de llevar a cabo un desarrollo fabril sistematizado, actitud que sí tuvieron los empresarios extranjeros que vinieron a colonizar las zonas de compleja geografía del sur de Chile"28.

Para Mazzei este tipo de actitud en la clase terrateniente se constituyó como una suerte de agricultura rutinaria; término que acuñó para definir apego a la rutina que tuvieron los hacendados en la región de Concepción respecto a la zona central. ${ }^{29}$ Lo anterior sugiere que, en el intento de inserción en la lógica capitalista de las provincias del sur, la posesión de la tierra va

\footnotetext{
${ }^{25}$ Ortega, L. 2005. Chile en ruta al capitalismo, Cambio, Euforia y Depresión. Santiago, LOM ediciones, DIBAM; Centro de Investigaciones Barros Arana, p. 25.

${ }^{26}$ Pinto Rodríguez, J. \& Órdenes Delgado, M. 2012. Chile, una economía regional en el siglo XX. La Araucanía, 1900 1960. Osorno, Ediciones Universidad de La Frontera. pp. 7 - 8.

${ }^{27}$ Ibid, p. 13.

${ }^{28}$ Bauer, A.1994. La sociedad rural chilena. Desde la conquista española a nuestros días. Santiago de Chile, Editorial Andrés Bello, p. 209.

${ }^{29}$ Mazzei De Gracia, L. 2001. "La agricultura de la región de Concepción durante el siglo XIX", en Academia Chilena de la Historia, Vida rural en Chile durante el siglo XIX, Santiago de Chile, 2001, pp. 201-232. P. 226. Ante este tipo de tendencia, Mazzei reconoce que hacia finales del siglo XIX los hacendados de Concepción estuvieron dispuestos a desprenderse de tal rutina y emprender el camino hacia la modernización agrícola mediante la creación de la Sociedad Agrícola del Sur (Hacendados de Concepción) en 1881 y de la Escuela Práctica de Agricultura en 1887. Sin embargo, para el autor, dicha intención habría sido tardía debido al fin de una etapa de expansión económica en la década de 1880, p. 232.
} 
a seguir una tendencia al orden tradicional que va a encontrar sus contradicciones con el desarrollo fabril ${ }^{30}$. Si bien la compra de tierras hacia el sur se acentuó por la necesidad de cubrir la demanda interna de productos agrícolas, una vez que se dio impulso a la industria salitrera en el norte grande del país, pareciera que fue básicamente un medio de ostentación de los nuevos ricos mineros y comerciantes ${ }^{31}$.

La Guerra del Pacífico (1879-1883) y la adquisición de la riqueza de los nitratos del norte grande, generaron un cambio en la economía nacional que evidentemente tuvo sus repercusiones en la zona sur. Pese al nuevo fenómeno de migración hacia los centros salitreros del norte grande desde la década de 1880 en adelante, la producción agropecuaria destinada a los mercados internos habría ido en aumento. No obstante, se ha señalado que, pese a las diversas crisis que asolaron al rubro agrícola a lo largo del siglo decimonónico, éste habría experimentado cambios dinámicos y una diversificación de los productos desde mediados del siglo XIX-a partir de la expansión de la economía exportadora-, que fueron aumentando incluso hasta la Gran depresión de $1929^{32}$. Sin entrar en mayor detalle, lo cierto es que el salitre trajo evidentes cambios en la economía y sociedad del país, especialmente, en lo que fue la aceleración del proceso de proletarización, la necesidad de aumentar la productividad y la modernización del campo y las zonas carboníferas. También la esfera política se vio beneficiada, por el valorado mineral salitrero, pues permitió un enriquecimiento de la clase dominante durante las décadas de la hegemonía parlamentaria. En efecto, el interés de la clase política, los empresarios extranjeros y, más aún, de los hacendados chilenos, se centró especialmente en la expansión de la frontera agrícola. Dicho interés Salazar lo explica de la siguiente manera:

“La expansión de la frontera agrícola hacia el sur mezcló, pues, la vieja acumulación primitiva con la moderna acumulación industrial, donde los nuevos conquistadores fueron los especuladores criollos (que se quedaron con la propiedad de la tierra) y la casa comercial extranjeras (que dieron a esta nueva colonización el 'toque' capitalista)."33

\footnotetext{
${ }^{30}$ Ante esta dicotomía, Luis Ortega señala que el "Si el sistema fabril, junto con la ciencia y la democracia, eran las fuerzas que desde los puntos de vistas económico, intelectual y político caracterizaban la evolución de las sociedades en camino hacia la modernidad, un tránsito efectivo requería de cambios profundos en los sistemas de tenencia de la tierra, en las relaciones sociales de producción e, inevitablemente, en el manejo del poder político." En suma, según este autor, la falta de estas actitudes y acciones por parte de la Élite chilena llevaría al fracaso de una industrialización plena en el país en el siglo XIX. En Ortega, L. Chile en ruta al capitalismo, Cambio, Euforia y Depresión, Óp. Cit., p. 27 y 469-473.

${ }^{31}$ Al respecto Arnold Bauer señala que los terratenientes chilenos del siglo XIX eran más urbanos que rurales y que carecían de interés por invertir capital en la producción agrícola para obtener mayores ganancias. Ver Bauer, A. 1994. La sociedad rural chilena., pp. $207-209$.

32 Robles Ortiz, C. 2009. “La producción agropecuaria chilena en la 'Era del Salitre' (1880-1930)”, América Latina en la Historia Económica, número 32, julio-diciembre, pp. 113-134.

${ }^{33}$ Salazar, G. 2003. Historia de la acumulación capitalista en Chile, 1a ed., Santiago de Chile, LOM Ediciones, p. 90.
} 
Aquí nuevamente se pone en discusión la dicotomía tradición-modernidad en el marco de los fuertes cambios económicos producidos a escala nacional. Si bien se ha dicho que desde la década de 1880, la dicotomía campo-ciudad se fue haciendo cada vez más estrecha debido al aumento sostenido de la población a escala nacional, lo que se tradujo en el surgimiento de un asalariado rural gracias al desarrollo de la minería en el Norte Salitrero-que influyó en el proceso de proletarización-, apreciamos que en el caso de las provincias del sur, las relaciones sociales de trabajo sufrieron cambios pero mantuvieron un carácter eminentemente tradicional hacia fines del siglo XIX asociado al mundo rural.

Cuadro N¹ Población por provincia y sexo en Chile $(1865-1895)^{34}$

\begin{tabular}{|c|c|c|c|c|c|c|c|c|c|c|c|}
\hline $\begin{array}{l}\text { Años/ } \\
\text { sexo }\end{array}$ & $\frac{0}{\frac{0}{3}}$ & 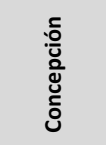 & 通 & $\begin{array}{l}\frac{0}{0} \\
\dot{o} \\
\frac{0}{0}\end{array}$ & $\frac{\stackrel{8}{d}}{\overline{\bar{N}}}$ & 突 & $\frac{\frac{\pi}{2}}{\frac{2}{0}}$ & $\begin{array}{l}\frac{0}{J} \\
\frac{c}{5} \\
\frac{5}{0} \\
\frac{D}{J}\end{array}$ & 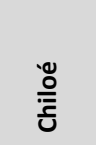 & 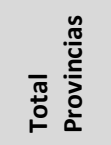 & $\frac{\frac{0}{\bar{C}}}{\frac{U}{\mathbb{J}}}$ \\
\hline 1865 & 125.409 & 146.056 & 71.901 & --- & --- & --- & 23.429 & 37.601 & 59.022 & 463.418 & \multirow{3}{*}{1.819 .223} \\
\hline Hombres & 61.268 & 72.026 & 37.299 & --- & --- & --- & 12.007 & 19.347 & 29.002 & 230.949 & \\
\hline Mujeres & 64.141 & 74.030 & 34.602 & --- & --- & --- & 11.422 & 18.254 & 30.020 & 165.842 & \\
\hline 1875 & 136.871 & 151.470 & 51.307 & 76.498 & 20.056 & --- & 30.525 & 48.492 & 64.536 & 579.755 & \multirow{3}{*}{2.075 .971} \\
\hline Hombres & 67.556 & 74.966 & 27.106 & 39.844 & 10.844 & --- & 15.840 & 25.163 & 31.522 & 292.851 & \\
\hline Mujeres & 69.315 & 76.504 & 24.201 & 36.654 & 9.212 & --- & 14.685 & 23.329 & 33.014 & 286.914 & \\
\hline 1885 & 149.871 & 182.459 & 93.625 & 101.768 & 81.767 & --- & 41.987 & 62.804 & 73.410 & 787.691 & \multirow{3}{*}{2.507 .005} \\
\hline Hombres & 72.779 & 91.382 & 48.898 & 53.301 & 44.583 & --- & 22.264 & 32.110 & 35.329 & 400.646 & \\
\hline Mujeres & 77.092 & 91.077 & 44.727 & 48.467 & 37.184 & --- & 19.723 & 30.699 & 38.091 & 387.060 & \\
\hline 1895 & 152.935 & 188.190 & 59.237 & 88.749 & 98.032 & 78.221 & 60.687 & 78.315 & 77.750 & 882.116 & \multirow{3}{*}{2.695 .625} \\
\hline Hombres & 74.291 & 91.998 & 30.326 & 44.663 & 51.734 & 40.935 & 31.416 & 40.366 & 36.414 & 442.146 & \\
\hline Mujeres & 78.644 & 96.192 & 28.911 & 44.086 & 46.298 & 37.286 & 29.271 & 37.949 & 41.336 & 439.973 & \\
\hline
\end{tabular}

Fuente: Elaboración propia a partir del resumen de la población del país realizado en el censo del año 1835 al de 1952 por provincias en XII Censo general de población y I de vivienda, Tomo I, Resumen del País, Servicio Nacional de Estadísticas y Censos, 1952. Pp. 38-39. Cifras corroboradas en los respectivos Censos.

En el cuadro $\mathrm{N}^{\circ} 1$, se expresa la cantidad de población total en Chile y de las provincias del sur según los registros de los últimos cuatro censos del siglo XIX. Se puede observar que la población total de éstas fue aumentando de modo directamente proporcional a la nacional entre 1865 y 1895 . En relación con la población a nivel nacional, el total de habitantes aumentó en ese lapso en un 29,4\%. Hacia 1885, los habitantes de estas provincias constituían el 31,4\% del total nacional, vale decir, cerca de un tercio. Por otro lado, en los veinte años que

\footnotetext{
${ }^{34}$ En este cuadro de población se consideran todas las edades y extranjeros. Cabe indicar que, en las cifras generales del censo de 1885, se incluyen a los extranjeros residentes en el país. Específicamente en cifras, la población extranjera por provincia para ese año fue la siguiente: en Ñuble, 263; Concepción, 1.634; en Arauco, 523; en Biobío 1.060; Territorio de Angol 2.963; Valdivia con 1.163; Llanquihue, 1.273; y Chiloé, 227.
} 
comprende el cuadro, en la mayoría de las provincias la población masculina superó a la femenina, salvo en las de Ñuble, Concepción y Chiloé, donde dicha tendencia es a la inversa, llegando la cantidad de mujeres a superar a la masculina.

Cuadro $\mathrm{N}^{\circ} 2$ de Población urbana y rural de las provincias del Sur

\begin{tabular}{|c|c|c|}
\hline Año & \% Población urbana & \% Población rural \\
\hline 1865 & 20,3 & 79,7 \\
\hline 1875 & 23,4 & 76,6 \\
\hline 1885 & 28,5 & 71,5 \\
\hline 1895 & 31,9 & 68,1 \\
\hline
\end{tabular}

Fuente: Elaboración propia a partir de Censos de los Años 1865, 1875, 1885,1895. Provincias de Ñuble, Concepción, Arauco, Biobío, Territorio de Angol, Valdivia, Llanquihue y Chiloé.

En el cuadro $\mathrm{N}^{\circ} 2$, resumimos en porcentajes la cantidad de población distribuida en las zonas urbanas y rurales de la totalidad de habitantes de las provincias. A partir de estas cifras, se puede establecer que, entre 1865 y 1895, en las provincias del sur hubo un aumento de la población urbana inversamente proporcional a la rural, de un $11,6 \%$. Sin embargo, la población rural se mantuvo todos los años sobre un $60 \%$ respecto de la urbana, la cual solo alcanzó a constituir un tercio de los habitantes del sur hacia finales del siglo XIX. 


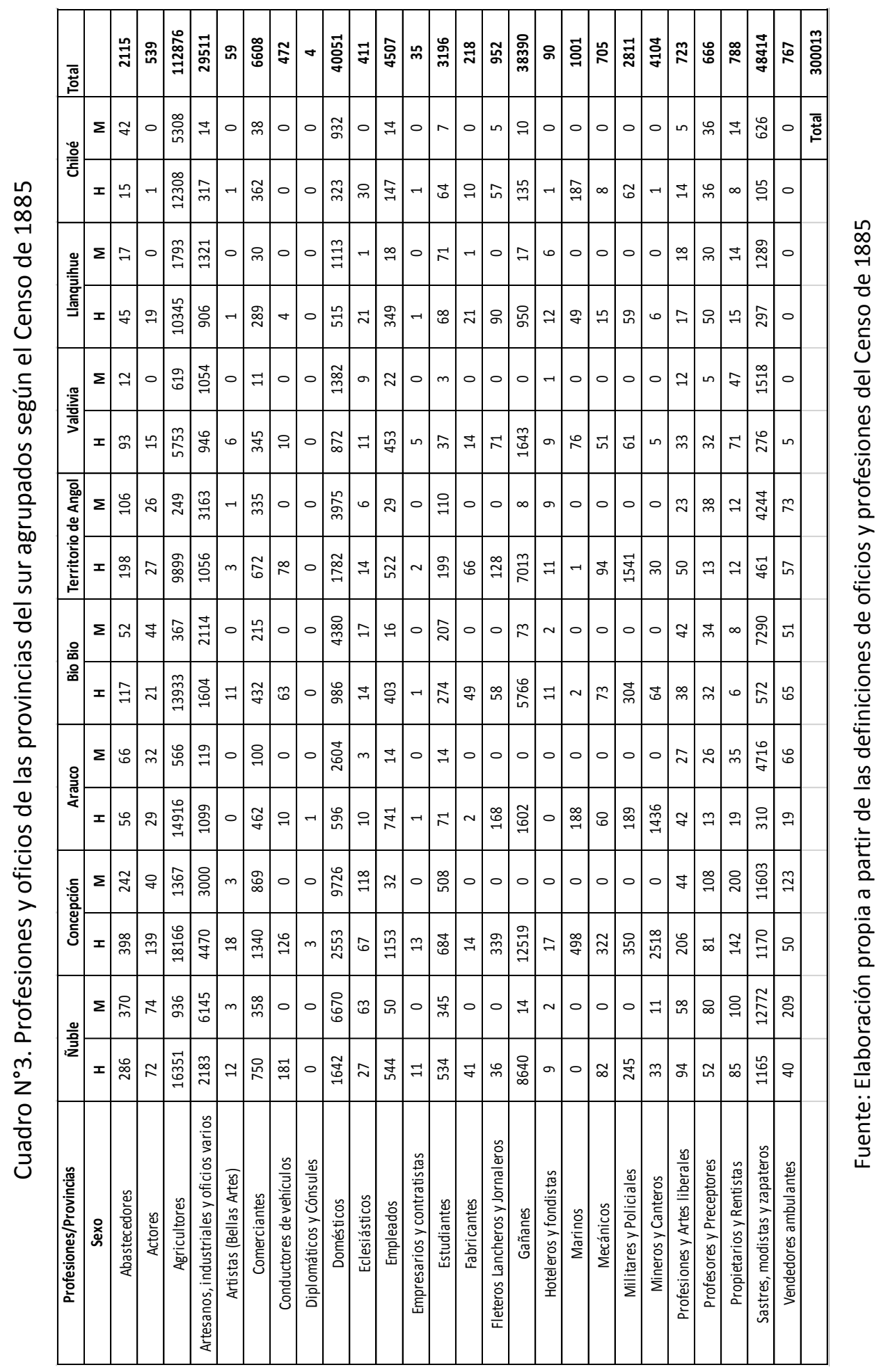


Las categorías laborales que se han adoptado para elaborar el cuadro $\mathrm{N}^{\circ} 3$ son las mismas que proporciona el censo de 1885. Desde aquí, también se han extraído los distintos tipos de peonaje presente en las provincias del sur, categorizados en el cuadro $\mathrm{N}^{\circ} 4$.

Cuadro $\mathrm{N}^{\circ} 4$ Peonaje total en las provincias del sur en $1885^{35}$

\begin{tabular}{|c|c|}
\hline Tipo de peonaje & Total en provincias del sur \\
\hline Gañanes & 37.278 \\
\hline Costureras & 41.832 \\
\hline Fleteros, lancheros y jornaleros & 800 \\
\hline Cocheros & 179 \\
\hline Cocinero & 8.482 \\
\hline Lavanderas & 12.240 \\
\hline Sirvientes & 16.058 \\
\hline Arrieros & 51 \\
\hline Nodrizas & 388 \\
\hline Total & 117.308 \\
\hline
\end{tabular}

Fuente: Elaboración propia a partir del censo de 1885.

Al analizar ambos cuadros, se puede afirmar que, del total de población económicamente activa de las provincias de Ñuble, Concepción, Arauco, Biobío, territorio de Angol, Valdivia, Llanquihue y Chiloé que, a saber, serían 300.013 trabajadores y trabajadoras, el $41 \%$ corresponderían a un peonaje urbano y rural. Si esto le sumamos la cantidad total de labradores registrados en todas las provincias-que vendrían a ser 8.204 personas - y la totalidad de vendedores ambulantes-758-dicha proporción aumentaría a un 44\%.

Para identificar a los sectores populares tanto urbanos como rurales, se han descontado desde la estructura de oficios y profesiones establecida en el cuadro $\mathrm{N}^{\circ} 6$, a los artistas, actores, comerciantes, conductores de vehículos, diplomáticos, empleados privados y públicos, eclesiásticos y religiosas, profesiones liberales, hoteleros y fondistas, constructores, empresarios, contratistas, propietarios y rentistas, militares y policiales, marinos, estudiantes y mecánicos. En efecto, queda una población de 120.309 trabajadores, que pertenecerían a los estratos más bajos de la sociedad, a la cual, si se le suma el total de peonaje, constituirían un $84 \%$ (155.583) de la población total de las provincias del sur. Un resultado similar obtuvo, sobre

\footnotetext{
${ }^{35}$ Se sigue el esquema presente en Salazar, G. 2015. Labradores, Peones y Proletarios, p. 157. Donde, al igual que Salazar, no se incluye el peonaje minero, aunque sí a los canteros; tampoco al peonaje militar e inquilinaje por no ser registrados por los censistas como tales.
} 
el universo de los sectores populares en la provincia de Concepción, Arnoldo Pacheco: $82,62 \%{ }^{36}$.

En resumen, desde el análisis realizado en los apartados anteriores, se concluye que, en primer lugar, si bien en las provincias del sur, en los años precedentes a la guerra civil de 1891, se estaba manifestando una paulatina urbanización asociada al proceso modernizador que se venía dando a escala nacional, más de la mitad de la población siguió habitando en áreas rurales. En segundo lugar, en la estructura laboral de las provincias se pudo identificar una suerte de convivencia entre oficios tradicionales de carácter agrícola con profesiones modernas y liberales de índole urbana. En tercer lugar, a partir de las profesiones registradas en el censo de 1885 , se puede deducir que un poco más del $80 \%$ de la población económicamente activa del sur estuvo constituida por sectores populares. Desde este grupo social fue reclutada la mayoría de los individuos de tropas que conformaron las fuerzas de línea en la Guerra Civil de 1891-y anteriormente, de la Guerra del Pacífico-.

\section{Despliegue y acuartelamiento de las tropas de las provincias del sur de Chile en la guerra civil de 1891.}

El Ejército de Chile, desde los tiempos de la Independencia, se ha caracterizado por ser una institución que ha permitido una movilidad social más allá del orden estamental gracias al mérito y capacidad personal; fenómeno social que es posible evidenciar, incluso, desde los tiempos de las milicias coloniales del siglo XVIII ${ }^{37}$. En efecto, el Ejército de Chile se podría considerar como una institución que ha replicado el orden social tradicional pero que, en palabras de Sergio Vergara Quiroz, "formó un grupo humano que contribuyó a la homogenización nacional y a la formación de los sectores medios, siendo un camino de ascenso social desde la Independencia y de consolidación mesocrática, hacia mediados del siglo XIX." ${ }^{38}$ En cambio, la Armada de Chile conservó un carácter elitista de difícil movilidad social, compuesta por una oficialidad rígida con una evidente influencia británica en su formación, donde el contraste socioeconómico con las capas más bajas dentro de sus miembros era mucho más marcado ${ }^{39}$.

En cuanto al proceso de profesionalización del Ejército de Chile, se trata de un proceso que se inició a comienzos del gobierno de José Manuel Balmaceda (1886-1891). Sus resultados no fueron inmediatos ni tampoco estuvieron exentos de problemáticas tanto dentro como fuera

\footnotetext{
${ }^{36}$ Pacheco, A. 2003. Economía y Sociedad de Concepción. Siglo XIX: sectores populares urbanos 1800-1885.Primera edición, Concepción, Universidad de Concepción, Facultad de Humanidades y Arte, Departamento de Ciencias Históricas y Sociales, p. 154.

37 Arancibia, P. 2007. El Ejército de los Chilenos (1540-1920), Santiago de Chile, Editorial Biblioteca Americana, primera edición, p. 45.

${ }^{38}$ Vergara Quiroz, S. 1993. Historia Social del Ejército, p.13.

${ }^{39}$ Ver Fuenzalida Bade, R. 1978. La Armada de Chile. Desde la alborada al sesquicentenario Vol. IV, Santiago, Empresa periodística Aquí Está.
} 
de la institución. En otras palabras, hubo un conflicto interno entre la oficialidad del Ejército y el recién asignado Emilio Körner, ante sus innovadoras modificaciones en la formación de oficiales. Por otro lado, en el exterior de la institución, persistía la problemática en torno a la actitud de los sujetos que se esperaba conformaran una tropa de línea profesional y disciplinada. En palabras de Körner, la tropa del Ejército chileno "lejos de ser una mezcla de todas las clases de la sociedad, se componía de las personas que no tenían capacidad o vocación para otra ocupación", agregando, también, que "la bebida y el juego además del vicio de la 'camaradería' -convivencia con mujeres sin mediar matrimonio-" ${ }^{40}$ eran los supuestos flagelos de este grupo social. Körner catalogaba a la soldadesca chilena como la escoria de la sociedad, lo que deducía a partir de los altos índices de deserción de la tropa, lo cual según él demostraba la baja moral de este escalafón militar. También menciona la incompatibilidad física de los soldados, a lo que habría que agregar la variedad de enfermedades que hacía aumentar las cifras de licenciamientos. Como se verá más adelante, tal situación de la tropa de línea no habría cambiado hasta una vez finalizado el conflicto armado de 1891.

\subsection{El estallido de la guerra civil y la organización de ambos ejércitos}

En términos generales, al observar la información proporcionada por las listas de revista de comisario, se constata que muchas de las unidades balmacedistas y congresistas adquirieron el nombre de la localidad de reclutamiento, con la excepción de aquellos cuerpos militares tradicionales ya existentes. En el caso de las fuerzas congresistas sucedió algo similar, se organizaron las unidades según los nombres de lugares, aunque muchas de ellas lo hicieron a partir de cuerpos de caballería ya existentes. En segundo orden, es notorio que el despliegue del contingente militar del bando presidencialista superó en elevada proporción al congresista, información deducida también a partir de las listas de revista, donde es posible identificar 74 y 31 cuerpos militares respectivamente ${ }^{41}$.

Se puede presumir que esta amplia magnitud de fuerzas balmacedistas-con excepción de los regimientos y algunos cuerpos de caballería y artillería - se vio favorecida por el sistema de movilización cívica de la Guardia Nacional que, en aquella época, era capaz de reclutar a lo largo del país a unos 40.000 individuos para la defensa nacional. Por su parte, el ejército congresista inicialmente pudo concentrar el grueso de su contingente en el norte grande, particularmente en Iquique y Antofagasta, y en algunas partes del norte chico, como en Coquimbo, Copiapó, Ovalle y Pozo Almonte. Pese a la gran capacidad de movilización estimada del Ejército Presidencialista, en mayor medida logró dotar de brazos para la guerra en el centro y sur del país, salvo algunas excepciones en que pudimos identificar algunos cuerpos movilizados $y$

\footnotetext{
${ }^{40}$ Cfr. Kórner, Emil, "Die historische Entwicklung der chilenischen Wehrkraft", separata del Militár-Wochenblatt, 5 (1910), pp. 131 a 174, en Arancibia, P. 2007. El Ejército de los chilenos, óp. Cit., pp. 204-205.

${ }^{41}$ Archivo de Histórico del Ejército de Chile (en adelante $A H E C H$ ). Listas de revista de comisario, vols. 179 al 201, año 1891.
} 
registrados en el norte chico. En concreto, se podría establecer que se trató de una guerra entre el norte y sur del país, entre un ejército tradicional y uno casi totalmente improvisado.

\subsection{El enganche de las tropas Balmacedistas en el sur del país}

El sur de Chile pese haber sido una zona en la cual se esperaba que se desarrollara el conflicto ${ }^{42}$, especialmente por la relevancia estratégica de los territorios carboníferos, quedó prácticamente relegada como zona de reclutamiento de tropa y recursos para el bando balmacedista. Según el informe elaborado por el ministro del Interior de Balmaceda, Julio Bañados Espinoza, la organización inicial del ejército balmacedista a nivel nacional comenzó a ejecutarse el 12 de enero y quedó compuesto por siete divisiones, distribuidas entre Santiago y Concepción. ${ }^{43}$

Hacia junio de 1891 las divisiones en el bando presidencialista se redistribuyeron y se calcula un total de fuerza efectiva de $\mathbf{2 8 . 0 0 0}$ personas movilizadas a nivel nacional. Entre ellos, los soldados y clases sumaban la cantidad de 26.340, mientras que los jefes y oficiales alcanzaban la suma de 1.664. En términos más específicos, la fuerza efectiva de jefes, oficiales y tropa en total por divisiones provinciales quedaba establecida de la siguiente manera: 1a División Santiago con 6.645; 2ạ División Valparaíso 5.926; 3ạ División Angol con 1.057; 4ạ División Concepción con 7.061; 5a División Coquimbo con 6.290; 7ạ División Valdivia, con 1.045 y un cuerpo llamado Diversas fuerzas con $1.644^{44}$.

El cuadro $\mathrm{N}^{\circ} 4$ especifica los nombres de los cuerpos y la cantidad de fuerza de la tropa del sur registrada hacia el 16 de agosto de 1891. Para ese entonces las divisiones balmacedistas se redujeron a cuatro. La División Concepción ocupó el último lugar y quedó compuesta a partir de los cuerpos movilizados en las provincias de Concepción, Biobío, Malleco, Cautín, Arauco y Valdivia, alcanzando un contingente militar sobre los 9.000 hombres, distribuidos en tres brigadas. Cabe señalar que se pudo percatar de la existencia de tropas desplegadas en las provincias de Valdivia, Llanquihue y Chiloé que correspondieron a la $10^{\circ}$ División Valdivia, compuesta principalmente por los batallones movilizados Valdivia y Llanquihue, el escuadrón movilizado Arique, las brigadas movilizadas de Puerto Montt y Osorno, y el Batallón Chiloé, con una dotación de 400 plazas $^{45}$. No obstante, este contingente se disolvió en el mes de junio de

\footnotetext{
${ }^{42}$ Núñez, J. 2003. 1891: Crónica de la Guerra Civil, Santiago de Chile, LOM Ediciones.

${ }^{43} 1$ a División, Santiago, jefe, General Orozimbo Barbosa; 2a División, Valparaíso, jefe, Coronel Gutiérrez; 3a División, Quillota, jefe, Coronel Carlos Wood; 4ạ División, Talca, jefe, Comandante Manuel Jesús Jarpa; 5a División, Chillán, jefe. Coronel Ruiz; 6a División, Angol, jefe, Coronel Solo Zaldivar; y la 7ạ División, Concepción Jefe, Comandante Daniel García Videla. Ver en: Bañados Espinoza, J. 1894. Balmaceda y su revolución, Tomo Il. París, Garnier, p. 103.

${ }^{44}$ ANCH. Fondo Ministerio de Guerra. Vol.1871. Resumen jeneral de Divisiones, 20 de junio de 1891, s/f.

${ }^{45}$ Archivo Nacional de Chile (en adelante $A N C H$ ), Fondo Ministerio de Guerra, Oficio de la Comandancia de Armas de la $10^{\circ}$ División de Valdivia al ministro de Guerra en Campaña. №61, 9 de marzo de 1891, s/f. En este informe se especifica que en hasta aquella fecha la cantidad de contingente de las unidades de la División Valdivia era la siguiente: Movilizado Valdivia con 350 plazas; el escuadrón movilizado Arique con 150 hombres; las brigadas
} 
1891, pasando sus unidades a formar parte de la $7^{\circ}$ División Concepción, aunque, como se verá, sólo el batallón Valdivia tuvo participación en las batallas cruciales.

Cuadro N4. Conformación final de la 4aㅡ División Concepción, 16 de agosto de 1891

\begin{tabular}{|c|c|c|}
\hline \multicolumn{3}{|c|}{ 4ta División Concepción } \\
\hline Brigada & Cuerpos & $\begin{array}{l}\text { Fuerza efectiva de } \\
\text { Tropa }\end{array}$ \\
\hline \multirow[t]{6}{*}{$1^{\circ}$ Brigada (Coronel Carlos Wood) } & Rejimiento Movilizado Arauco & 773 \\
\hline & Batallón Movilizado Yumbel & 517 \\
\hline & Batallón Movilizado Nacimiento & 465 \\
\hline & Batallón Movilizado Anjeles & 552 \\
\hline & Batallón Movilizado Valdivia & 330 \\
\hline & Escuadrón Collipulli & 190 \\
\hline \multirow[t]{7}{*}{$2^{\circ}$ Brigada (Coronel Federico Castro) } & Rejimiento Movilizado Santiago & 1044 \\
\hline & Batallón Movilizado Nueva Imperial & 456 \\
\hline & Batallón Movilizado Linares & 632 \\
\hline & Batallón Movilizado Concepción & 376 \\
\hline & Batallón Movilizado Tomé & 395 \\
\hline & Batallón Movilizado Angol & 389 \\
\hline & Escuadrón Húsares & 185 \\
\hline \multirow[t]{10}{*}{$\begin{array}{l}3^{\circ} \text { Brigada (Coronel Florentino } \\
\text { Pantoja) }\end{array}$} & Rejimiento Tacna $n^{\circ} 2$ de línea & 1112 \\
\hline & $\begin{array}{c}\text { Batallón Mov. Gendarmes de } \\
\text { Concepción }\end{array}$ & 534 \\
\hline & Escuadrón Concepción & 385 \\
\hline & Brigada Mov, Artillería de Concepción & 385 \\
\hline & Batallón Mov. Artillería de Marina & 768 \\
\hline & Batallón Movilizado Lontué & 73 \\
\hline & Compañía Coraceros & 88 \\
\hline & Escuadrón Malleco & 208 \\
\hline & Escuadrón Nueva Imperial & 175 \\
\hline & Compañía de Pontoneros & 68 \\
\hline \multicolumn{2}{|c|}{ Total de fuerza } & 9.715 \\
\hline
\end{tabular}

Fuente: Elaboración propia a partir de Fondo Varios, Vol. 538, Listado de Brigadas, jefes y fuerza efectiva de la Cuarta División Concepción, s/f, 16 de agosto de 1891.

\subsection{La controversia del reclutamiento forzoso en el despliegue de las tropas del sur}

Desde el momento en que ocurrió la sublevación de la Escuadra, el presidente Balmaceda decretó Estado de Asamblea en todo el territorio nacional, asumiendo "el ejercicio de todo el 
poder público necesario para la administración y gobierno del Estado" ${ }^{46}$. En consecuencia, se fueron asignando fondos a las gobernaciones provinciales para enganches, ranchos y defensas de ciudades, pueblos y puertos. De este modo, comenzó el reclutamiento de manera masiva a lo largo del país.

En la prensa del sur fue posible encontrar un caso donde se evidencian irregularidades en el reclutamiento de individuos. En Lebu, por ejemplo, se presta atención a este asunto de la siguiente manera:

"Lebu, 4 de marzo de 1891:

Habiendo llegado a conocimiento de esta Comandancia Jeneral que individuos armados se finjen comisiones reclutadoras, i comenten, a la sombra de este engaño, toda clase de violencias i depredaciones; decreto:

$1^{\circ}$ No se tendrán por comisiones autorizadas, sino las que exhiban órdenes escritas de esta Comandancia Jeneral, o de los Comandantes de Armas respectivos.

$2^{\circ}$ Déjanse sin efecto las autorizaciones que se hubieren conferido a particulares antes de esta fecha.

$3^{\circ}$ Los que infrinjieren el presente decreto serán sometidos para su castigo, al conocimiento de la justicia ordinaria por los delitos que cometieren.

Anótese, comuníquese a los Comandantes de Armas de los departamentos para que llegue a conocimiento de todos. Vásquez Guarda” ${ }^{47}$.

Al parecer, esta tergiversación del enrolamiento tuvo una rápida reacción por parte de las autoridades y el ejército. Más al sur, en la Araucanía, estas anomalías en el proceso de reclutamiento resultaron alarmante para Gustave Verniory, ingeniero extranjero que estuvo en Temuco, Lautaro y Victoria durante su estadía en Chile, y escribió su experiencia durante la Guerra Civil de 1891. Este personaje relata que durante los primeros meses del conflicto:

"Los caballeros entran en él como oficiales, y los soldados se toman entren los rotos, la plebe de aquí. Entonces ahora hay que reclutarlos, y el modo de hacerlo es de lo más original [...]En Lautaro han principiado por tomar a todos los hombres válidos en las calles, sin ocuparse de saber si estaban cargados de familia, si eran propietarios de una casita, y si sólo una pequeña cosecha les permitía vivir. Naturalmente, nadie se atrevía a salir; el que se mostraba en la calle era tomado inmediatamente. Como el procedimiento ya no rendía nada, los reclutadores comenzaron a entrar a las casas para reclutar a los hombres que pudieran encontrar. Los que escaparon huyeron a los bosques, de manera que, en Lautaro, fuera de los notables, los extranjeros, mis mozos y los soldados, no se veía ni un solo representante del sexo fuerte [...]Mientras la ciudad se limpiaba así, las comisiones recorrían

\footnotetext{
${ }^{46}$ El Bio Bío, Los Ángeles, 11 de enero de 1891.

${ }^{47}$ El Arauco, Arauco, 15 de abril de 1891.
} 
los campos aprehendiendo a todo hombre que trabajara en las tierras. Naturalmente que las faenas o campamentos de obreros del ferrocarril no fueron perdonados. En el momento menos pensado, los soldados hacían irrupción llevándose a todos cuantos podían alcanzar" $^{\prime 8}$.

Obreros y peones habrían sido los principales blancos de estas comisiones según Verniory. Sin duda se trataba de un abuso de autoridad que contrastaba con aquellas noticias de la prensa gobiernista que describía la calma y buena disposición de los hombres que se enrolaban en el ejército buscando defender a la patria.

Por otra parte, en el contexto de reclutamiento de gente en la provincia de Arauco, en febrero de 1891 se informaba por la prensa gobiernista que: "más de 700 trabajadores de diferentes establecimientos carboníferos, de Lota, Lebu i otros puntos, han sido puestos a las órdenes del gobierno por los empresarios de aquellos establecimientos que han paralizado sus operaciones" ${ }^{\prime 9}$. No es de extrañar que tal medida fuera oportuna para el gobierno e Balmaceda, ya que la zona del carbón resultaba ser un lugar estratégico para la Escuadra, que enviaba recurrentemente al crucero Esmeralda hacia las costas de Arauco en busca del preciado combustible presente allí.

Si bien Bañados insistía en que se buscaban todos los estímulos tanto monetarios como morales para no quebrantar la iniciativa del soldado, el fenómeno de enganche forzoso a lo largo del país fue un evento que indudablemente llevaron a cabo principalmente los agentes del gobierno balmacedista, que posteriormente fueron procesados ${ }^{50}$. Lo anterior puede explicar el hecho que el gobierno de Balmaceda, una vez que comenzó el despliegue de cuerpos cívicos a lo largo del país, alcanzó una alta cantidad de contingente de manera rápida, considerando que también hubo enganches por primas de dinero.

En definitiva, según Bañados-sea cual fueren los mecanismos utilizados-, los enganches realizados entre el 7 de enero y el 29 de julio en las provincias del sur, dieron paso a la siguiente conformación de unidades de infantería: los Batallones Linares, Concepción, Tomé, Yumbel, Angeles, Angol (dos cuerpos distintos), Traiguén, Nacimiento, Mulchén, San Carlos, Nueva Imperial, Collipulli, Valdivia, Chiloé y Artillería de Marina (que luego pasa a Brigada). ${ }^{51}$ Asimismo, se levantaron tropas de línea de las siguientes Brigadas cívicas: Lebu, Arauco, Bulnes,

\footnotetext{
${ }^{48}$ Verniory, G. 2001. Diez años en Araucanía, 1889-1899, Segunda edición, Santiago de Chile, Pehuén Editores, pp. 168-169.

49 El Colono, Angol, 11 de febrero de 1891. Noticia también publicada en el diario presidencialista en La Paz, de Rio Bueno, 19 de febrero de 1891.

${ }^{50}$ Este ministro señala en su testimonio que "más de un abuso aislado habría aquí y allá; pero nunca serían tan numerosos que pudieran establecer una regla [...] En los primeros días, á fin de reunir en el menor tiempo posible el mayor número de soldados, se multiplicaron, quizás con exceso, los centros de enganche y la formación de Batallones y Brigadas." Ver Bañados Espinoza, J. 1894. Balmaceda, su gobierno y la revolución de 1891, Tomo II. P. 106.

51 Ibid, p. 106.
} 
Yungay, Penco, Cañete (que pasa de Escuadrón a Brigada posteriormente), Victoria (que pasa luego a Batallón), y Coronel. Sólo le faltó a este ministro mencionar los cuerpos cívicos de Artillería de Tomé y Puerto Montt, y a la Brigada Cívica de Río Bueno, que figuran en las listas de revista de Comisario. En suma, según los cálculos de Bañados, hubo en dicho período un total de 43 Batallones y 16 Brigadas de infantería movilizadas a lo largo del país para el Ejército presidencialista. ${ }^{52}$ Del total, las fuerzas de línea del sur correspondieron al $35 \%$ y $50 \%$ respectivamente. A lo anterior habría que sumarle las fuerzas de línea cívicas movilizadas en las ramas de Artillería y Caballería, lo cual aumentaría aún más aquella proporción.

\section{Acuartelamiento de las Tropas del Sur y sus principales problemáticas}

Como se señaló más arriba, al estallar el conflicto entre el Ejecutivo y el Congreso, la zona sur del país resultaba ser un espacio estratégico para ambos bandos. El Correo del Sur, a inicios de enero de 1891, mencionaba al respecto que "Concepción figura como centro vital para la concentración de tropas movilizadas de Yumbel, Puchacai y de las provincias de Ñuble y Maule $^{253}$.

A partir de las ubicaciones de los distintos cuerpos movilizados presentes en el cuadro $\mathrm{N}^{\circ} 5$, en una primera formulación se puede establecer que los principales desplazamientos de las tropas reclutadas en el sur convergieron finalmente entre Concepción y Talcahuano, resultando ser ciudades concéntricas para las unidades militares que posteriormente fueron enviadas al norte. Además, se pudo identificar que también hubo algunos movimientos hacia la zona norte del país e incluso hacia la costa central antes de la concentración final de la 4a División en Concepción realizada en agosto. Por otro lado, es notorio que las unidades militares se fueron trasladando entre las provincias y particularmente la provincia de Malleco resultó ser un territorio de paso para los cuerpos cívicos movilizados.

\footnotetext{
52 Ídem.

${ }^{53}$ El Correo del Sur, Concepción, 19 de enero de 1891.
} 
Cuadro $\mathrm{N}^{\circ} 5$. Unidades militares balmacedistas del Sur y sus ubicaciones por ciudad y provincia entre enero y agosto de 1891

\begin{tabular}{|c|c|c|c|}
\hline \multirow[b]{2}{*}{ Unidad Militar del Sur } & \multicolumn{3}{|c|}{ Ubicaciones entre enero y agosto de 1891} \\
\hline & Ciudades & $\begin{array}{l}\text { Provincia/ } \\
\text { zona }\end{array}$ & Meses \\
\hline \multirow[t]{2}{*}{ Regimiento Chorrillos $\mathrm{N}^{\circ} 9$ de línea } & Concepción & Concepción & Febrero \\
\hline & Valparaíso & Zona central & Marzo / Abril /Mayo / Junio /Julio \\
\hline \multirow[t]{2}{*}{ Regimiento Cívico Movilizado Chillán } & Chillán & Ñuble & Enero /Febrero \\
\hline & Santiago & Zona central & Marzo \\
\hline \multirow[t]{2}{*}{ Regimiento Cívico Movilizado Santiago } & Santiago & Zona central & Febrero \\
\hline & Concepción & Concepción & Marzo / Abril / Mayo /Junio \\
\hline \multirow[t]{3}{*}{ Regimiento de Carabineros de Yungay } & Temuco & Cautín & Enero / Febrero / Marzo \\
\hline & Angol & Malleco & Enero \\
\hline & Valparaíso & Zona central & Marzo / Abril / Mayo / Junio / Julio / Agosto \\
\hline \multirow[t]{3}{*}{ Regimiento de Zapadores de línea } & Talcahuano & Concepción & Enero \\
\hline & Copiapó & Norte chico & Enero \\
\hline & Caldera & Norte chico & Enero \\
\hline \multirow[t]{2}{*}{ Regimiento Esmeralda $7^{\circ}$ de línea } & Santiago & Zona central & Marzo / Abril / Mayo / Junio / Julio \\
\hline & Chillán & Ñuble & Febrero \\
\hline \multirow[t]{4}{*}{ Regimiento Movilizado Arauco } & Lota & Arauco & Mayo / Junio \\
\hline & Arauco & Arauco & Enero \\
\hline & Laraquete & Arauco & Febrero \\
\hline & Coronel & Arauco & Junio \\
\hline Regimiento Tacna $2^{\circ}$ de línea & Concepción & Concepción & $\begin{array}{l}\text { Enero / Febrero / Marzo / Abril / Mayo /Junio / } \\
\text { Julio / Agosto }\end{array}$ \\
\hline Brigada Cívica Bulnes & Bulnes & Ñuble & Enero / Febrero /Marzo \\
\hline Brigada Cívica Movilizada Coronel & Coronel & Arauco & Febrero \\
\hline Brigada Cívica Movilizada de Artillería Tomé & Tomé & Concepción & Enero \\
\hline Brigada Cívica Movilizada de Nueva Imperial & $\begin{array}{l}\text { Nueva } \\
\text { Imperial }\end{array}$ & Cautín & Enero \\
\hline Brigada Cívica Movilizada de Penco & Penco & Concepción & Febrero / Marzo / Abril / Mayo \\
\hline \multirow[t]{3}{*}{ Brigada Cívica Movilizada de Temuco } & Temuco & Cautín & Enero / Febrero \\
\hline & Traiguén & Cautín & Marzo \\
\hline & Viña del Mar & Zona central & Abril / Mayo / Junio / Julio / Agosto \\
\hline \multirow[t]{3}{*}{ Brigada de Artillería de Marina } & Santiago & Zona central & Sin registro \\
\hline & Talcahuano & Concepción & Febrero / Marzo /Abril / Junio / Julio \\
\hline & Concepción & Concepción & Junio \\
\hline Brigada Movilizada de Artillería Concepción & Concepción & Concepción & Abril / Mayo / Junio \\
\hline Brigada Movilizada Lebu & Lebu & Arauco & Enero / Febrero \\
\hline \multirow[t]{2}{*}{ Brigada Cívica de Artillería de Puerto Montt } & $\begin{array}{l}\text { Puerto } \\
\text { Montt }\end{array}$ & Llanquihue & Enero \\
\hline & Valdivia & Valdivia & Agosto \\
\hline Brigada Cívica de Rio Bueno & Rio Bueno & Llanquihue & $\begin{array}{l}\text { Enero / Febrero / Marzo / Abril / Mayo/Junio } \\
\text { /Julio /Agosto }\end{array}$ \\
\hline Brigada Movilizada Osorno & Osorno & Llanquihue & Enero / Ferero / Marzo \\
\hline \multirow[t]{6}{*}{ Batallón Esmeralda $\mathrm{N}^{\circ} 7$} & Chillán & Ñuble & Enero / Febrero /Marzo \\
\hline & Concepción & Concepción & Enero \\
\hline & Talca & Zona central & Enero \\
\hline & Lebu & Arauco & Enero \\
\hline & Talcahuano & Concepción & Enero \\
\hline & Santiago & Zona central & Abril /Mayo / Junio /Julio /Agosto \\
\hline
\end{tabular}




\begin{tabular}{|c|c|c|c|}
\hline Unidad Militar del Sur & \multicolumn{3}{|c|}{ Ubicaciones entre enero v agosto de 1891} \\
\hline \multirow{5}{*}{ Batallón Cívico Movilizado Linares } & Ciudades & \begin{tabular}{|l|} 
Provincia/ \\
zona
\end{tabular} & Meses \\
\hline & Linares & Zona central & Febrero \\
\hline & Lota & Arauco & Marzo \\
\hline & Santiago & Zona central & Febrero \\
\hline & Tupiza & Zona norte & Abril \\
\hline Batallón Cívico Movilizado Los Angeles & Talcahuano & Concepción & Febrero / Marzo /Abril /Mayo \\
\hline Batallón Cívico Movilizado Tomé & Tomé & Concepción & Febrero \\
\hline & Angol & Malleco & Marzo /Abril /Mayo /Junio \\
\hline Batallón Cívico Movilizado Yumbel & Tomé & Concepción & Enero / Febrero / Marzo / Abril / Mayo / Junio \\
\hline Batallón Movilizado Angol & Angol & Malleco & Enero / Julio \\
\hline & Talcahuano & Concepción & Abril / Mayo / Junio \\
\hline Batallón Movilizado Collipulli & Collipulli & Malleco & Enero \\
\hline & Angol & Malleco & Febrero / Marzo \\
\hline Batallón Movilizado Concepción & Penco & Concepción & Junio \\
\hline Batallón Movilizado Mulchén & Mulchén & BioBío & Enero \\
\hline & Angol & Malleco & Febrero \\
\hline & Calama & \begin{tabular}{|l|} 
Norte \\
Grande \\
\end{tabular} & Marzo \\
\hline & Antofagasta & & Marzo \\
\hline & $\begin{array}{l}\text { Tupiza/Zapig } \\
\text { a? }\end{array}$ & Norte & Abril \\
\hline & Los Andes & Zona central & Mayo \\
\hline & Santiago & Zona central & Junio / Julio \\
\hline Batallón Movilizado San Carlos & San Carlos & Ñuble & Febrero /Marzo / Mayo / Junio / Julio \\
\hline & Talcahuano & Concepción & ??? \\
\hline & Chillán & Ñuble & Abril \\
\hline Batallón Movilizado Traiguén & Coronel & Arauco & Marzo / Abril \\
\hline & Talcahuano & Concepción & Mayo / Junio / Julio \\
\hline Batallón Cívico Nueva Imperial & $\begin{array}{l}\text { Nueva } \\
\text { Imperial }\end{array}$ & Cautin & Enero / Marzo \\
\hline & \begin{tabular}{|l} 
Bajo \\
Imperial \\
\end{tabular} & Cautín & Enero / Febrero \\
\hline & Temuco & Cautín & Febrero \\
\hline & Angol & Malleco & Abril \\
\hline & Concepción & Concepción & Mayo \\
\hline Batallón Movilizado Nacimiento & Nacimiento & BioBío & Febrero \\
\hline & Collipulli & Malleco & Marzo \\
\hline & Concepción & Concepción & Abril \\
\hline & Talcahuano & Concepción & Mayo / Junio / Julio / Agosto \\
\hline & Lota & Arauco & Agosto \\
\hline Batallón Movilizado Victoria & Victoria & Cautín & Febrero \\
\hline & Angol & Malleco & Marzo \\
\hline & Valparaiso & Zona central & Abril / Junio / Julio \\
\hline & \begin{tabular}{|l} 
San \\
Bernardo
\end{tabular} & Zona central & Enero \\
\hline Batallón Cívico Movilizado Llanquihue & Valdivia & Valdivia & Agosto \\
\hline Batallón Valdivia & Valdivia & Valdivia & Enero / Febrero \\
\hline & San José & Valdivia & Enero \\
\hline Batallón Movilizado Chiloé & Ancud & Chiloé & Febrero / Marzo \\
\hline & Castro & Chiloé & Marzo \\
\hline
\end{tabular}




\begin{tabular}{|c|c|c|c|}
\hline Unidad Militar del Sur & \multicolumn{3}{|c|}{ Ubicaciones entre enero y agosto de 1891} \\
\hline \multirow{3}{*}{ Ciudades } & $\begin{array}{l}\text { Provincia/ } \\
\text { zona }\end{array}$ & Meses & Enero \\
\hline & Lebu & Arauco & Febrero \\
\hline & Cañete & Arauco & Mayo / Junio / Julio \\
\hline \multirow{2}{*}{$\begin{array}{l}\text { Escuadrón Cívico Movilizado Húsares de la } \\
\text { Frontera }\end{array}$} & Angol & Malleco & Febrero / Marzo / Abril \\
\hline & Concepción & Concepción & Mayo / Agosto \\
\hline \multirow{2}{*}{$\begin{array}{l}\text { Escuadrón Cívico Movilizado Húsares de } \\
\text { Temuco }\end{array}$} & Temuco & Cautín & Marzo / Abril / Mayo \\
\hline & Angol & Malleco & Junio \\
\hline Escuadrón Movilizado de Collipulli & Concepción & Concepción & Marzo / Abril \\
\hline Escuadrón Movilizado de Malleco & Angol & Malleco & Mayo / Junio / Julio \\
\hline \multirow[t]{2}{*}{$\begin{array}{l}\text { Escuadrón Movilizado de Caballería Volante } \\
\text { de Imperial }\end{array}$} & $\begin{array}{l}\text { Nueva } \\
\text { Imperial } \\
\end{array}$ & Cautín & Enero / Febrero / Marzo / Abril / Mayo / Junio \\
\hline & Temuco & Cautín & Junio \\
\hline
\end{tabular}

Fuente: Elaboración propia a partir de Fuente: Elaboración propia a partir de Listas de Revista de Comisario Vols. 179 al 201, año 1891, Archivo Histórico del Ejército de Chile.

Las listas de revista de comisario también proporcionan datos sobre la serie de problemáticas que afectaron a las unidades movilizadas y acuarteladas en el sur. Concretamente, se trata de licenciamientos, deserciones, enfermedades, expulsiones y muertes que en las listas figuran, en conjunto, como "bajas". En ellas se detallan, además, el nombre y rango de los sujetos que figuran bajo esta condición, lo cual permitió distinguir entre jefes, oficiales, clases y soldados.

En el gráfico $N^{\circ} 1$, se estableció el total de 3.177 bajas registradas, que corresponde solo a los individuos en calidad de "soldados" de las 43 unidades militares que fueron movilizadas en las provincias del sur entre los meses de enero y agosto. Aquí, evidentemente, podemos apreciar que las enfermedades y las deserciones fueron las principales bajas de la tropa alcanzando cifras similares entre sí y superando en grandes proporciones al resto de las otras bajas.

En cuanto a las bajas por enfermedad, en la mayoría de los casos los soldados aparecían registrados "como presentes", "enfermos en el hospital", "enfermos en el lazareto", "enfermos en la ambulancia". Muchos soldados se encontraban en dichos lugares de manera ambulatoria o bien durante varios meses, pues los nombres en las listas se van repitiendo mes a mes, aunque en ningún caso se indica la causa de enfermedad. Cuando llegaban a fallecer, se entregaba información sobre la causa siendo la más recurrente la viruela. Sin embargo, es necesario aclarar que hubo también casos de pulmonía, escarlatina y tifus que afectaron a la tropa guarnecida en las provincias del sur, aunque el registro de estas enfermedades es aún más escaso que el de la viruela ${ }^{54}$. Ante esto, no es de extrañar que las condiciones de salubridad en los cuarteles hayan potenciado el desarrollo de aquellas enfermedades.

\footnotetext{
${ }^{54}$ Se indican como fallecido por escarlatina al soldado Víctor Arenas del Regimiento Cívico Movilizado Santiago, el 25 de abril de 1891. En esta misma unidad y mes se registra el fallecimiento por pulmonía del soldado Liborio Droguett. Muerto por esta última causa en julio figura el soldado Victorino Ibarra del Regimiento Carabineros de Yungay.
} 
Gráfico N¹.

Bajas de la totalidad de las tropas del sur registradas en listas de revista de comisario entre enero y agosto de 1891

\section{BAJAS}

3000

2500

2000

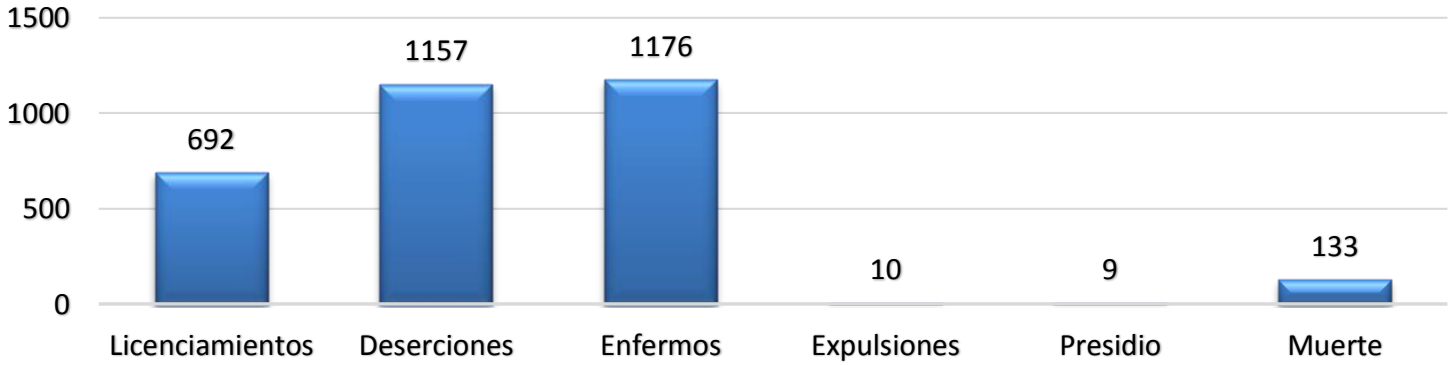

Fuente: Elaboración propia a partir de Listas de Revista de Comisario Vols. 179 al 201. Archivo Histórico del Ejército de Chile.

Al tratarse de un despliegue masivo se tuvo que recurrir al uso de establecimientos privados y fiscales que fueran capaces de albergar a una gran cantidad de individuos de tropa. Entre las propiedades que fueron ocupadas por el ejército presidencialista en la zona sur solamente se logró identificar las que se encontraban en Concepción y Talcahuano. En la primera, estaba "la cómoda i estensa casa de Gregorio Burgos, uno de los cabecillas de la oposición” ${ }^{55}$ que funcionó como cuartel a partir de mediados de enero. A su vez, en esta misma ciudad, el Batallón Linares se instaló en el edificio del convento de San Francisco, lugar que no presentaba las condiciones necesarias para acuartelar a estos individuos. Así se detallaba las características de este cuartel en la prensa:

"Por lo infestado que se halla diariamente el aire que rodea a ese local, parece que no se han construido logares a propósito. De consiguiente, llamamos la atención del Estado Mayor sobre ese defecto, porque bien puede ser fatales las consecuencias para la salubridad pública. Los vecinos de los cuatro costados de dicha manzana nos comunican que es inaguantable el mal olor que se nota en el espresado cuartel. Asi mismo nos avisan que

${ }^{55}$ El Lautaro, Coronel, 16 de enero de 1891. 
varias noches se han sentido griterías i desórdenes, que es preciso reprimir en bien de la misma disciplina" ${ }^{56}$.

En Talcahuano se debieron ocupar bodegas fiscales y recintos privados que, según la gobernación, fueron arrendados a módicos precios ${ }^{57}$, así lo expresaba, por ejemplo, el Intendente Echeverría al presidente Balmaceda: "Tropa está bien alojada, ocupando bodegas fiscales, casas municipales i de particulares, pagándose módicos arriendos, habiéndose arreglado en ellas camillas i entarimados. Aquí todo tranquilo" ${ }^{58}$. No obstante, recién el 15 de julio en este puerto estaban reparados los cuarteles para los batallones Ángeles, Traiguén, Angol y Nacimiento. ${ }^{59}$

Las deserciones resultaron ser también el fenómeno más recurrente entre las tropas provinciales del sur. Casi en la totalidad de los casos registrados en las listas de revista de comisario, se precisa el nombre del individuo y día y mes de tal acometido. Ante tal situación, en el mes de junio, los parlamentarios balmacedistas tomaron cartas en el asunto decretando una amnistía a los desertores del ejército gobiernistas. Dicha resolución, que pasó a convertirse en ley, hacía un llamado a los soldados:

"que hasta el $1^{\circ}$ del actual [junio] hubieren cometido primera o segunda deserción sin circunstancia agravante, con tal que hayan sido aprehendidos antes de la vijencia de esta lei, o que voluntariamente se presenten al respectivo cuerpo o a alguna comandancia de armas dentro de los treinta días siguientes a su publicación" ${ }^{\prime 60}$.

\footnotetext{
${ }^{56}$ La Opinión, Traiguén, 15 de abril de 1891.

${ }^{57}$ Un ejemplo sobre la cantidad de estos gastos en Intendencia de Concepción. ANCH, Oficio de gobernación de Talcahuano, №202, 15 de junio de 1891, s/f. Ahí se señala "la casa amueblada perteneciente al señor Lucas Sanhueza que ocupa la Comandancia, Jefes y oficiales del Batallón de Artillería de Marina (\$125) ciento veinte y cinco pesos; por la casa de altos perteneciente al Sr. Juan Martínez Ramos para alojamiento de jefes y oficiales del Batallón Angol $(\$ 80.00)$ ochenta pesos; por la bodega y casa de altos perteneciente a la sucesión del Sr. Luis Mathieu la suma de (\$300) tres cientos pesos y por la casa para Comandancia y alojamiento de jefes y oficiales del Batallón Nacimiento, cuya propiedad es de la Sra. Florinda Lynsay v. de Evans, la suma de (\$90.00) noventa pesos. La casa del Sr. Lucas Sanhueza [...] se tomó en arriendo el día 1 de abril; la del Sr. Juan Martinez Ramos para el Angol, el 22 de marzo; la bodega y casa de altos de la sucesión del Sr. Luis Mathieu, el 21 de abril y la casa de la sra. Florinda Linzay v. de Evans, el 6 de mayo. Para el piquete de Húsares destacado en San Vicente, se ha ocupado desde el 13 de mayo una casa para oficiales, de propiedad de doña Visenta Aguayo, por el cánon $(\$ 10.00)$ diez pesos mensuales; otra casa del Sr. Nicolás Pardo, para la tropa por $(\$ 15.00)$ quince pesos y dos galpones, uno para pesebreras y otro para guardar forrajes y hacer el rancho por $(\$ 10.00)$ diez pesos mensuales cada uno. El primero pertenece al Sr. Enrique Schuyler y el segundo a Pastor Martínez."

${ }^{58} \mathrm{ANCH}$, Intendencia de Concepción, Vol. 806. Telegrama de José Echeverría al Sr. J.M. Balmaceda. 9 de julio de $1891, \mathrm{~s} / \mathrm{f}$.

${ }^{59}$ ANCH, Intendencia de Concepción. Vol. 821. Gobernación de Talcahuano, Informe de José Echeverría. N²03, 15 de junio de $1891, \mathrm{~s} / \mathrm{f}$.

${ }^{60}$ El Ñuble, Chillán, miércoles 10 de junio de 1891.
} 
Lamentablemente no se pudo constatar la efectividad de aquél llamado. Es más, fue reiterada la publicación a través de la prensa del bando enviado por el coronel Jorge Wood, comandante del regimiento movilizado Arauco, balmacedista. En él se señalaba lo siguiente:

"Teniendo presente que conviene á los intereses del regimiento engrosar sus filas, Ilamando á sus banderas a los individuos que las han abandonado en momentos de irreflexión ó por efecto de pérfidas instigaciones, y de los cuales muchos se hallan actualmente asilados y bajo el amparo de los establecimientos carboneros del sur de Concepción, con esta fecha he resuelto lo siguiente:

Desde hoy en doce días todo individuo del regimiento que, habiendo incurrido en deserción se presente a su cuartel, será indultado de toda pena corporal.

Aquellos que desoyendo este jeneroso llamamiento, no acudieren a su cuartel, serán perseguidos con todo teson, y una vez habidos, castigados con todo el rigor de la ley marcial Lota, Agosto $1^{\circ}$ de 1891. Jorge Woodd A $^{\prime 61}$

Por lo visto, las deserciones solían ser una respuesta negativa a las condiciones propias del soldado común de aquél entonces, quien prácticamente no tenía una preparación militar adecuada o simplemente no quería formar parte de la contienda.

Dentro de las bajas registradas, los licenciamientos ocuparon un tercer lugar. La mayoría de los soldados fueron licenciados por inutilidad física. Luego, en orden descendiente, le siguieron aquellos licenciamientos por no convenir al servicio; por dejar sustitutos-entre los cuales no se especifica la razón-por inepto o inútil; por orden del alto mando y por estar enfermos; por incorregible; y finalmente aquellos "licenciados", entre los que no se detalla causa alguna.

A síntesis, ante las bajas por deserciones y licenciamientos, se puede afirmar que aquél sujeto al cual las autoridades aspiraban a transformar en un soldado, en la mayoría de los casos, no contaban con las condiciones ni con con las aptitudes para tal efecto.

\section{La participación y desenlace de las tropas del sur en las batallas cruciales de la guerra civil de 1891: pozo Almonte, Concón y Placilla}

\subsection{Pozo Almonte}

Según lo que se ha planteado anteriormente, y considerando la manera en cómo se desarrollaron las batallas de Pozo Almonte, Concón y Placilla, el principal matiz entre los ejércitos movilizados, fue que presidencial, si bien contó con una importante cantidad de soldados, tendió a dispersarse fácilmente, tanto en la movilización como posteriormente en el campo de batalla. En tanto, el ejército congresista se fue conformando de manera improvisada y aumentando su dotación en la medida en que avanzaba hacia el sur.

${ }^{61}$ Los Tiempos de Talca, miércoles 5 de agosto de 1891. 
Sobre la participación de las tropas del sur en aquellas batallas, ya se ha señalado que algunos cuerpos militares del sur fueron movilizados hacia el norte, entre febrero y marzo, en auxilio de las tropas gobiernistas que allí se encontraban. El batallón Temuco, que contaba con 300 plazas, comenzó su viaje el día 12 de febrero ${ }^{62}$. Días más tarde el Batallón Angol fue enviado en el "Matías Cousiño" hacia Arica, lugar en el que desembarcó el 18 de febrero. Por otra parte, en el mes de marzo, dos compañías del Batallón Mulchén fueron enviadas hacia Antofagasta y luego ubicadas en Calama, aunque no fue posible encontrar información relacionada a la participación de esta unidad en algún combate. Misma situación nos ocurrió al seguir el rastro del Batallón Victoria, el cual fue enviado a Santiago el 17 de marzo, para luego ser trasladado en tren especial a Valparaíso ${ }^{63}$.

Sin embargo, del Angol, junto con algunos individuos del Tacna $2^{\circ}$ de línea, sí se pudo obtener cierta información acerca de su desenlace en la batalla de Pozo Almonte. Una parte del contingente del batallón Angol se encontró en el hospital San Agustín de Valparaíso, específicamente: dos sargentos, ocho cabos y 30 soldados. En este mismo recinto, se registraron seis individuos del Tacna $2^{\circ}$ de línea, entre los cuales uno era un sargento y el resto cinco soldados. El resto de los sujetos pertenecientes al batallón Angol se encontraban en el Hospital del Liceo de Iquique, y eran precisamente 12 soldados $^{64}$.

Según los listados presentes en la prensa del período, de los 322 soldados del batallón Angol que participaron en la Batalla de Pozo Almonte, 41 resultaron heridos. En cuanto a los posibles muertos, lamentablemente no fue posible encontrar información alguna, ni siquiera de los desaparecidos ni de aquellos soldados que se dispersaron en otros cuerpos, especialmente, en la División Camus que inició su retirada hacia Bolivia a fines de marzo ${ }^{65}$. En resumen, la batalla de Pozo Almonte vino a sellar las campañas que se fueron desarrollando en el Norte debido al triunfo congresista. Si bien el hundimiento del Blanco Encalada, ocurrido el 23 de abril de 1891, significó un fuerte golpe a la moral de los revolucionarios y la frustración de una posible tregua

\footnotetext{
${ }^{62}$ La Voz, Traiguén, 12 de febrero.

${ }^{63}$ El Colono, Angol, 1 de abril de 1891.

${ }^{64}$ Algunos de los heridos del batallón Angol que participaron en Pozo Almonte y que se registraron en la prensa, fueron: "José Mellado, brazo izquierdo, leve. Fabriziano Fuentes, costado izquierdo, leve. Manuel Jesús Sanhueza, brazo izquierdo, leve. Antonio Inostroza, pierna derecha leve. Jenaro Betancourt, costado izquierdo, leve. Fidel Maldonado, pierna derecha, leve. Marcos Correa, brazo i costado izquierdo, leve. José H. Ponce, amputado el muslo derecho." En El Colono, Angol, sábado 2 de mayo de 1891.

${ }^{65}$ No obstante, en un documento del bando congresista se informa sobre los siguientes oficiales muertos, heridos y prisioneros del Batallón Angol: Coronel comandante don Manuel Rumminot, muerto; Sarjento Mayor don Manuel Antonio Jarpa, herido i prisionero; Capitán ayudante Pedro Pablo muerto; Capitan Salvador Meza, muerto; Teniente Manuel Garrido, prisionero; Teniente Pedro María Navarrete, herido; Teniente Rafael Milner, herido y prisionero; Teniente Luis Gonzalez, muerto; Daniel Alvarez, herido y prisionero, subteniente Francisco Cáceres, muerto. El resto de los nombres que figuran no se distinguen en la documentación y otros no indican estado de individuo. Asimismo, no se mencionan a oficiales del Tacna $2^{\circ}$ de línea. ANCH. Fondos Varios, Vol. 539. Lista de bajas de jefes y oficiales del Batallón Angol en Batalla de Pozo Almonte. P. 376.
} 
entre las partes en disputa, finalmente el avance y ocupación de la zona centro sur era un asunto crucial para los congresistas, especialmente para darle fin al conflicto.

\subsection{La movilización de las tropas del Sur hacia el centro del país}

Para el mes de agosto, la División Concepción no se encontraba en condiciones óptimas para iniciar una completa movilización de su contingente hacia el lugar que fuese necesario. En efecto, el ministro Bañados, al realizar su visita a las tropas que se encontraban guarnecidas en Concepción y Talcahuano, concluyó lo siguiente:

"resultaba que el 7 de Agosto le faltaba a la división de Concepción: Las Ambulancias; Carabinas y sables para casi toda la Caballería; Cañones para la Artillería, la que tenía seis cañones Amstrong de montaña y sólo cuatro Krupp de campaña, con cuatro ametralladoras Catling: Caballos para gran parte de la Caballería: Mulas para el servicio sanitario, para el parque y para la Artilleria: Armamento menor para la Artillería divisionaria; Cananas y caramayolas para casi toda la división Uniformes, botas y frazadas para más de un tercio de la misma; Rifles uniformes para un quince por ciento y varios otros artículos indispensables para salir á campaña" ${ }^{66}$.

Al parecer, la escasez de pertrechos para la tropa no se debió a la falta de gestión de sus comandantes, sino que sus necesidades no fueron oportunamente atendidas por el alto mando de Santiago durante el transcurso del acuartelamiento. Además, al tratarse de una movilización masiva, era de esperarse que este tipo de problemas estuvieran a la orden del día, entre los cuales destacaba la escasez de armamento para gran parte de la división. Por vía telegráfica, el comandante García Videla realizó insistentemente una serie de peticiones de armamento y municiones para el sur, ante lo cual no se pudo encontrar evidencia de que dicha solicitud haya sido oportunamente atendida. ${ }^{67}$

Sobre la movilización de tropas del sur hacia la zona central es importante señalar que, a partir de junio, una parte importante de las unidades del sur comenzaron a trasladarse hacia Santiago y Valparaíso con el objetivo de integrarse a las $1^{\circ}$ y $2^{\circ}$ Divisiones del ejército balmacedista que, respectivamente, allí se hallaban. En dicho mes, el batallón Angol fue enviado a Santiago con un contingente de 100 hombres para formar parte del $4^{\circ}$ de línea acuartelado en esa ciudad. ${ }^{68}$ Un mes después, también fue enviada hacia la capital una fuerza del batallón Traiguén. Ambas fueron destinadas a la $1^{\circ}$ División dirigida por el General Barbosa. Posteriormente, en agosto, el mismo destino tuvieron el Regimiento Esmeralda $7^{\circ}$ de línea,

\footnotetext{
${ }^{66}$ Ibid. P. 463.

${ }^{67}$ ANCH. Fondo Ministerio del Interior, Telegramas enviados a Comandante en Jefe de la División de Concepción. Sólo nos encontramos con información sobre el envío por ferrocarril de 600 rifles al comandante García Videla desde Valparaíso. ANCH. Intendencia de Concepción Vol. 821, Comunicado de la Intendencia de Valparaíso $n^{\circ} 253$, al comandante de la División Concepción, 25 de enero de 1891.

${ }^{68}$ Intendencia de Concepción, Telegrama de José Echeverría a coronel Marchant en Santiago, 18 de junio de 1891.
} 
Chillán $8^{\circ}$ de línea y Mulchén, los cuales asistieron las filas de aquella división en Santiago. ${ }^{69}$ Por su parte, también a inicios de agosto, los Regimientos Lautaro $10^{\circ}$ de línea y Carabineros de Yungay; y los Batallones Temuco y Victoria pasaron a formar parte de la $2^{\circ}$ División en Valparaíso. Finalmente, a mediados de dicho mes, otros cuerpos que inicialmente se conformaron en las provincias del sur, fueron destinados a la División Coquimbo. Entre estas unidades estuvieron los Regimientos Movilizados Chillán, Zapadores e Imperial. ${ }^{70}$

En síntesis, previamente al traslado a Santiago, las fuerzas de la 4a División de Concepción se fueron diseccionando. Lo mismo fue ocurriendo una vez que se dio orden de trasladar la División hacia la zona central el día 20 de agosto con cerca de 7.000 efectivos.

\subsection{Concón y Placilla}

Recién entre el 20 y 21 de agosto se pudo comenzar a trasladar el grueso de la fuerza de la División de Concepción hacia Santiago. En efecto, casi la totalidad de las tropas del sur no participaron en la Batalla de Concón. Solamente lo hicieron las unidades que fueron enviadas previamente desde el sur, entre ellas, los cuerpos militares del sur presentes aquel día fueron: Temuco, Victoria-con 400 hombres cada uno-y Chorrillos $9^{\circ}$ de línea-con 532 hombres-; y con los batallones Mulchén y Traiguén - con 550 y 400 hombres, respectivamente-.

En Placilla, el coronel Wood con el regimiento Arauco se concentró en Quillota, mientras que el resto de la división se movilizaba al campo de batalla sumándose a unos 3.000 hombres que no combatieron en Concón ${ }^{71}$.

El cuadro $\mathrm{N}^{\circ} 6$, sintetiza aquellos cuerpos movilizados del sur presentes en la Batalla de Placilla los cuales, en suma-considerando además los que ya tuvieron participaciónconstituyeron casi el $70 \%$ del ejército presidencialista presenta aquél día, que en total fueron 6.300 hombres.

Aquél fatídico día, según el parte de Estanislao del Campo, las bajas del ejército congresista alcanzaron un total de 1.800. En detalle, los muertos revolucionarios fueron 4 jefes, 18 oficiales y 463 individuos de tropa; heridos 8 jefes, 75 oficiales y 1.041 de tropa; y desaparecidos a 191 individuos. Por su parte, los cálculos del mismo parte sobre los balmacedistas arrojaron 941 individuos de tropa muertos y 2.422 heridos, lo que da un total de 3.363 bajas $^{72}$. En resumen, Bañados concluye que, en total, los caídos entre muertos y heridos de ambos bandos en la Placilla fue de $5.163 .^{73}$ En Concón solo los muertos de ambos bandos fueron 2.869. Según estos

\footnotetext{
${ }^{69}$ Así se indican el informe de unidades que participaron en la parada militar de aquella división, detallado en Los tiempos de Talca, martes 4 de agosto de 1891.

${ }^{70}$ ANCH. Fondo Varios. Vol. 538. Lista de cuerpos, jefes y fuerza efectiva de a Quinta División Coquimbo, 16 de agosto de 1891, p. 134.

${ }^{71}$ Núñez, J. 1991. 1891. Crónica de la guerra Civil. P. 88.

72 Estanislao, DEL CAMPO, Memorias militares. óp. cit., p. 507. Las cifras de este parte realizado por Del Canto son consideradas por Bañados en su obra. En Bañados, óp. cit., p. 576.

${ }^{73}$ Bañados E. J. 1892. Balmaceda, su gobierno y la revolución de 1891, p. 576.
} 
cálculos, las dos últimas batallas de la guerra civil habrían significado al país más de ocho mil bajas.

Cuadro N6. Fuerzas del Sur presentes en la Batalla de Placilla el 28 de agosto de 1891

\begin{tabular}{|c|c|}
\hline Unidades & Cantidad \\
\hline Regimiento Tacna 2 ${ }^{\circ}$ de línea & 800 \\
Regimiento Santiago & 800 \\
Regimiento Arauco & 700 \\
Batallón Valdivia & 300 \\
Batallón Linares & 450 \\
Batallón Nacimiento & 550 \\
Batallón Angol & 450 \\
Batallón Concepción & 350 \\
Batallón Tomé & 350 \\
Brigada de Artillería de Concepción & 300 \\
\hline Total & 5.500 \\
\hline
\end{tabular}

Fuente: Elaboración propia a partir de Julio Bañados, Balmaceda, su gobierno y la revolución de 1891.

Tomo II. pp. 555-556.

\section{La difícil estabilización del orden social en el sur del país.}

La derrota balmacedista significó un peligro para aquellas personas que apoyaron la causa presidencialista, lo que se reflejó en la violencia desencadenada contra estas personas y sus propiedades a lo largo del país ${ }^{74}$.

En el sur, ocurrieron una serie de casos aislados que se desarrollaron en los días inmediatos al término de la guerra civil, eventos de desorden público que se les le atribuyó esencialmente al bajo pueblo. La embriaguez, el robo, los saqueos e incendios provocados a propiedades fueron la tónica de este tipo de violencia popular. La reorganización de la seguridad de las provincias recaía completamente en las autoridades civiles con el aparente apoyo de la población civil y soldados licenciados. Pese a esto, en los meses venideros, continuaron los desmanes postconflicto en las provincias del sur. En Coronel, por ejemplo, el día 20 de septiembre, una turba de trabajadores recién pagados y en su mayoría embriagados "se fueron sobre la quincena para saquearla. Tropa hizo fuego desde adentro a puertas cerradas i han resultado cuatro muertos" ${ }^{\prime 75}$.

En el sur del país, este tipo de evento se informaba por la prensa a través de la siguiente manera: "Vandalaje en la Frontera. Es extraordinario el desarrollo del vandalaje en la frontera,

\footnotetext{
${ }^{74}$ Sobre la ola de violencia producida en el país luego de la guerra civil, Venegas señala que una de las secuelas de esta fue: "el recrudecimiento del bandolerismo. Las armas y municiones que quedaron en el campo de batalla fueron un botín para quienes ya estaban al margen de la sociedad. Pero la guerra también dejó gente al borde de ella que pudo ver en el bandolerismo una forma de sobrevivencia." Ver: Venegas, F. 2013. "Los sujetos populares en la Guerra Civil de 1891", p.77.

${ }^{75}$ ANCH. Intendencia de Concepción, N810, Telegrama enviado por Larenas al Intendente de Concepción, 20 de septiembre de 1891.
} 
según las noticias que siempre están llegando. Parece que se están tomando activas medidas para tranquilizar a los hacendados, estirpando de raíz el mal" ${ }^{\prime 76}$. Dichas medidas consistían en traer fuerzas de línea para aplacar los diversos eventos de violencia asociado al bandidaje. En la Araucanía, por ejemplo, hacia inicios de diciembre, el boletín del día publicaba la siguiente noticia:

"El asalto a mano armada, el abijeato, el homicidio i el hurto, en fin, en toda forma, implantados en la frontera como industrias corrientes por partidas de desalmados, van a ser normalizados por la acción salvadora de las fuerzas del ejercito que cubren estas guarniciones" ${ }^{\prime 77}$.

Dicha noticia, además, fue específica al señalar que se habían enviado destacamentos de tropas a Curacautin, Quillen, Quino, Victoria, Quechereguas, Collipulli, Mininco, Sauces, Lumaco y Purén. El propósito era resguardar las propiedades y aplacar el terror de las fechorías cometidas por bandoleros.

En resumen, uno de los efectos materiales de la guerra civil que remecieron al país fue el bandolerismo o bandalaje, en un evidente escenario de difícil reorganización política. Bajo este contexto, estas problemáticas se vieron acentuadas en la zona sur por la difícil cobertura que el Estado podía garantizar en ese momento. Es más, hacia finales de junio de 1892, el problema se hizo sentir incluso en la esfera política de país, específicamente en el parlamento. El diputado Enrique Montt intervino en una sesión de la cámara señalando lo siguiente:

"Juzgo necesario llamar hoy la atención del Gobierno y de la Cámara hacia un mal de notoria gravedad y que exige pronto y enérgico remedio. Me refiero al bandolerismo, que ha comenzado a desarrollarse con alarmantes proporciones y con caracteres de espantosa crueldad en diversas provincias de la República. La prensa de todo el país aparece ordinariamente llena de asesinatos, salteos y violaciones. La seguridad de la vida, del honor y de los bienes ha desaparecido en los campos y en las ciudades mismas. Se mata y roba con igual frecuencia y facilidad en Santiago y en Unión, en Valparaíso y en la frontera, en los centros de grandes policías" ${ }^{78}$.

Según lo expuesto por el diputado, el bandolerismo era un problema recurrente y generalizado en el país, pero lo que resulta aún más llamativo sobre este diagnóstico, es el vínculo que establece entre el bandolerismo y la guerra civil-aludiendo por lo demás a otras causantes-en la siguiente intervención:

\footnotetext{
${ }^{76}$ La Libertad Católica, 18 de noviembre de 1891.

${ }^{77}$ El Araucano, Angol, 7 de diciembre de 1891.

${ }^{78}$ Boletín de las Sesiones Ordinarias de la Cámara de Diputados1892. Santiago de Chile, Sesión 5ạ ordinaria en 21 de junio de 1892. Intervención del diputado Enrique Montt.
} 
“¿Cuáles son las causas del bandolerismo que hoy hace estragos en el país? Ellas no son seguramente otras que la mala educación del pueblo, comprendiendo en ella los malos hábitos y los malos ejemplos, la falta de instrucción, el cultivo de la flojera y del ocio, la impunidad y el alcoholismo [...] Hay también otra causa que tiene un carácter ocasional y es la pasada guerra civil." ${ }^{79}$

Esto reafirma los planteamientos de Venegas señalados anteriormente donde la guerra generó las condiciones propicias para que estos sujetos que, desocupados y entrenados en las armas, vieran en el robo a mano armada un medio de subsistencia ${ }^{80}$.

Dos meses más tarde, en noviembre, también por medio de la prensa, se señala que tropas del ejército constitucional se hallaban estacionadas "en los diversos puntos de la República", siendo explicitados de la siguiente manera:

“Constitución n²1 en Santiago; Valparaíso n², Valparaíso; Pisagua n³, San Bernardo; Maipo $n^{\circ} 4$, Concepción; Batallón $n^{\circ} 5$, Temuco; Batallón n6, lquique, Arica y Pisagua; Batallón n8, Talcahuano; Artillería $n^{\circ} 1$ y 2, Santiago; Artillería ${ }^{\circ} 3$, Valparaíso; Granaderos, Santiago; Húsares, Angol; Carabineros, Angol; Injenieros, Santiago." ${ }^{81}$

La distribución territorial de estas unidades evidentemente se trataba de un plan de seguridad por parte del nuevo gobierno, especialmente por la concentración de gran parte de aquellas fuerzas en la zona sur de Chile.

\section{Una deuda social pendiente. El debate político en torno a la ley de pensiones.}

Desde un plano jurídico político, en primer lugar, la junta de gobierno, bajo la representación de Jorge Montt, realizó una ley de amnistía que comenzó a ejecutarse en diciembre de 1891, la cual apuntaba a establecer una política de olvido y conciliación con los colaboradores del presidente Balmaceda ${ }^{82}$. Sin entrar en detalles en este asunto, es importante aquí dilucidar los aspectos sociales subyacente a ese proceso.

Uno de los beneficios que, previamente a la guerra civil de 1891, favorecía a los veteranos del ejército, eran las gratificaciones económicas establecidas en la Ley de pensiones y montepíos del 22 de diciembre de 1881, fijada para aquellas personas que participaron en las campañas de la Guerra del Pacífico. No obstante, para el caso de la guerra civil de 1891, este beneficio tuvo limitaciones para quienes integraron las fuerzas balmacedistas, pues, en junio de 1892 la Junta de Gobierno estableció una ley que acordó el sueldo por un año solo a los heridos

\footnotetext{
79 Ídem.

${ }^{80}$ Venegas, F. 2013. “Los sujetos populares en la Guerra Civil de 1891.” p.77.

${ }^{81}$ La Discusión, Chillán, 22 de noviembre de 1891.

${ }^{82}$ Tema estudiado por Loveman, B. \& Lira, E. 1999. Las suaves cenizas del olvido. Vía chilena de reconciliación política 1814-1932.
} 
del ejército Constitucional ${ }^{83}$. Por consiguiente, los vencidos tuvieron que esperar por este beneficio a lo menos hasta el año 1933.

El camino recorrido por esta ley fue bastante extenso y fue precisamente en la esfera legislativa donde estuvo detenida por largo tiempo. En el congreso, las voces de los personeros políticos se alzaron, cada cierto tiempo, haciendo ver la necesidad de reformar la ley de 1881. Inicialmente, esta controversia se inició en la cámara de diputados el 27 de agosto de 1892, momento en que el diputado Ossa señaló que:

"Estoy recibiendo constantemente solicitudes de viudas de militares muertos en Concón y la Placilla, y solicitud de militares sobrevivientes de esos combates, por las que piden pensiones a que creen tener derecho" ${ }^{84}$.

Luego de su intervención, el parlamentario realizó la moción de preparar un proyecto de ley general de recompensas que beneficiara a los sobrevivientes y familiares de los muertos en las últimas campañas de 1891, insistiendo en hacer extensiva a estas personas los efectos de la ley de 1881. Esta propuesta no tuvo eco en la cámara de diputados. Tiempo después, fue retomada en el senado, en la sesión del 25 de agosto de 1902. En aquel momento, el Senador Elías Balmaceda realizó una intervención en la que explicó que, hasta aquella fecha, los ex soldados balmacedistas, en especial los inválidos, aún no recibían recompensas económicas. Sobre esto, el congresista señala:

"Hai un proyecto que parece digno de la pronta consideración del Congreso, i que ha venido retardándose para dar paso a otros asuntos que tienen preferencia en la tabla. Me refiero al proyecto que concede a los individuos pertenecientes al Ejército o buques que sirvieron a las ordenes del Gobierno de 1891 i que hubieren quedado inválidos, derecho a disfrutar de los beneficios de la lei de setiembre de $1881^{\prime \prime}{ }^{85}$.

Esta moción sería retomada al día siguiente, por el Senador Manuel Ballesteros, que se envolvió en una acalorada discusión con el senador Walker Martínez, quien insistía en disuadir el tema de la ley de pensiones argumentando que:

\footnotetext{
${ }^{83}$ Boletín de las leyes i decretos del gobierno. Tomo I. Primer cuatrimestre de 1892. Santiago de Chile. Imprenta nacional calle la Moneda, n`112. 1893. P. 277. Presidente de la Junta de Gobierno, Jorge Montt, Santiago, 11 de junio de 1892. Dicha ley establece que "Los heridos del Ejército constitucional deberán gozar por el término de un año, a contar desde la fecha de la promulgación de la lei de 9 de enero del año actual, el sueldo fijado por los decretos de 8 de mayo i 9 de junio de 1891 de la Excma. Junta de Gobierno, debiendo acreditar mensualmente por un certificado del Director del Servicio Sanitario que se encuentran medicinándose de sus heridas o que tramitan su espediente de invalidez i han obtenido informe favorable de la comisión de cirujanos encargada de su exámen."[sic]. ${ }^{84}$ Boletín de sesiones ordinarias de la cámara de diputados, sesión 32a ordinaria del 27 de agosto de 1892, intervención del diputado Ossa.

${ }^{85}$ Boletín de las Sesiones Ordinarias de la Cámara de Senadores. Sesión 41ạ ordinaria en 25 de agosto de 1902. Intervención del senador Elías Balmaceda.
} 
"no se trata de un proyecto de lei tan sencillo que podamos despacharlo sin mayor estudio [...] Hai razones que pueden ser morales o políticas pero hai otras mui atendibles e interesantes relativas al gasto [...] ¿Cuántos son los inválidos a quienes se quiere favorecer? ¿Qué gravamen se impondrá al Erario?”" ${ }^{86}$.

Ballesteros respondió que, básicamente, se trataba de un gravamen de $\$ 18.000$, y que la ley buscaba hacerse cargo de:

"simples soldados que, cualquiera sea la opinión que se tenga de los sucesos políticos de 1891, no tenían por qué creer que no era mui justa la causa que defendían, i que por defenderla, cumpliendo con su deber, quedaron mutilados e invalidos para ganarse la vida con su trabajo; i es justo que se le de lo mismo que se ha dado a los que se encontraron en las filas opuestas, para los cuales se han decretado leyes especiales de invalidez. Repito que este es, a mi juicio, un acto de evidente justicia, que nada tiene que ver con la cuestión que, con tanto calor, ha estado ventilando el señor Senador por Santiago [Walker Martínez] Por eso, me permito insistir en la indicación que he formulado." ${ }^{87}$

Favorablemente, al día siguiente este proyecto de ley fue puesto en votación, siendo aprobada por la cámara por catorce votos a favor y seis en contra. Pero, en realidad, la problemática de las remuneraciones militares tuvo ciertos matices, de manera intermitente en el tiempo, problemática que necesariamente debe estudiarse a fondo.

\section{Conclusiones}

En este estudio se ha podido lograr analizar, bajo la perspectiva social y regional una serie de fenómenos asociados a la conformación y despliegue de las tropas balmacedistas del sur. En primera instancia, se pudo constatar que la forma en que fue reclutado el contingente del sur se aplicaron tanto los mecanismos de reclutamiento forzosos como voluntarios, cuyos matices de algún modo deberían seguir profundizándose en investigaciones historiográficas posteriores, especialmente en el primer caso, pues la representación histórica de la experiencia vivida del soldado chileno no solo se debería limitar a evidenciar las glorias en el combate. En este sentido, se pudo evidenciar una resistencia de aquellos sujetos ante este tipo de acciones a través de los altos índices de deserción que fueron manifestando, fundamentalmente, los soldados de tropa durante el transcurso de la guerra civil.

En segundo lugar, fue gravitante hallazgo en esta investigación el hecho de que el despliegue de la división del sur tuvo como resultado la conformación una de las unidades militares más grandes del ejército presidencialista, acercándose a la cifra de 10.000 personas. Sin embargo,

\footnotetext{
${ }^{86}$ Boletín de las Sesiones Ordinarias de la Cámara de Senadores Sesión 42a ordinaria en 26 de agosto de 1902. Intervención del senador Walker Martínez.

${ }^{87}$ Ídem. Intervención del senador Elías Balmaceda.
} 
algunos de los cuerpos militares de esta división se fueron trasladando hacia el norte durante los inicios del conflicto, mientras que el resto se fue mermando en la medida en que se iban trasladando hacia la zona central del país.

Ahora bien, entre la serie de aspectos que tuvieron las pérdidas humanas de esta gran masa de individuos, las fuentes permitieron establecer, entre las denominadas "bajas", las características que tuvieron los licenciamientos y heridos. Se pudo ver en detalle la inhabilidad de muchos individuos y también las diferentes descripciones de los tipos de lesiones y enfermedades que reflejan la crudeza de este tipo de enfrentamiento.

Por otro lado, en lo que respecta a los muertos en combate, fue difícil e imprecisa la tarea de identificar causas e incluso nombres, por lo que, en la mayoría de los casos, se pudo establecer cifras estimativas. En lo que concierne a la acción en combate de las unidades militares del sur en las batallas decisivas de la guerra civil, vale decir, Pozo Almonte, Concón y Placilla, éstas se encuentran mencionadas en la documentación de carácter militar, desde las cuales fue posible confirmar que en Placilla participó más de la mitad del contingente reclutado inicialmente en las provincias del sur.

Finalmente, en lo referente a las consecuencias en larga duración de la guerra civil chilena en el sur, resultó preocupante observar lo difícil que fue para el nuevo gobierno restablecer el orden público, debido al bandolerismo que se desató, problemática que es necesario estudiar a cabalidad. También se hace necesario profundizar en el debate político-jurídico que surgió en los tiempos posteriores a la guerra civil en torno a la ley de pensiones, ya que en el último apartado de este estudio, se pudo concluir que se trata de uno de los temas que aún quedan pendientes por aclarar dentro de los efectos que tuvo este conflicto, especialmente en los sectores más bajos de la sociedad. En suma, este fragmento de historia social de la guerra deja más cuestionamientos que certezas.

\section{Bibliografía}

Arancibia, P. 2007. El Ejército de los Chilenos (1540-1920), Santiago de Chile, Editorial Biblioteca Americana, primera edición.

Bade, R. 1978. La Armada de Chile. Desde la alborada al sesquicentenario Vol. IV, Santiago, Empresa periodística Aquí Está

Bañados Espinoza, J. 1894. Balmaceda, su gobierno y la revolución de 1891, Tomo II, París, Garnier.

Bauer, A.1994. La sociedad rural chilena. Desde la conquista española a nuestros días. Santiago de Chile, Editorial Andrés Bello.

Collier, S. \& Sater, W. 1998. Historia de Chile, 1808-1994, Cambridge, U.K.: Cambridge University Press. Del Campo, E. 1927. Memorias militares del general D. Estanislao del Campo, Santiago, Imp. La tracción.

Donoso, C. \& Couyoumdjian, J. R. 2005. "De soldado orgulloso a veterano indigente. La Guerra del Pacífico. En Sagredo, R. \& Gazmuri, C. 2005. Historia de la vida privada en Chile. El Chile Moderno de 1840 a 1925. Tomo 2, Santiago de Chile, Aguilar Chilena de Ediciones S.A.

Encina, F. A. 1952. Historia de Chile. Desde la prehistoria hasta 1891, Tomo XX, Santiago, Editorial Nascimento. 
Gaddis, J. 2002. El paisaje de la historia. Cómo los historiadores representan el pasado, Barcelona, Editorial Anagrama.

Home Valenzuela, D. 2006. Los huérfanos de la Guerra del Pacífico: El "Asilo de la Patria", 1879-1885. Santiago, Colección Sociedad y Cultura, Centro de Investigación Diego Barros Arana, LOM Ediciones.

Jobet, J. C. 1955. Ensayo crítico del desarrollo económico-social de Chile, Santiago de Chile, Editorial Universitaria.

León, L. 2011. Ni patriotas ni realistas. El bajo pueblo durante la Independencia de Chile 1810-1822, Santiago de Chile, Ediciones de la Dirección de Bibliotecas. Archivos y Museos.

Loveman, B. \& Lira, E. 1999. Las suaves cenizas del olvido. Vía chilena de reconciliación política 18141932, Tomo I, Santiago de Chile, LOM ediciones.

Mayorga, R.; Neut, P. [Et. al]. 2008. Lejos del ruido de las balas: la guerra civil chilena de 1891, Santiago de Chile, Centro de Estudios Bicentenarios.

Mazzei De Gracia, L. 2001. "La agricultura de la región de Concepción durante el siglo XIX", en Academia Chilena de la Historia, Vida rural en Chile durante el siglo XIX, Santiago de Chile, 2001. Pp. 201-232.

Méndez Notari, C. 2009. Héroes del Silencio. Los Veteranos de la Guerra del Pacífico (1884-1924), Santiago, Ediciones Centro de Estudios Bicentenario

Miño, M. 2002. “¿Existe la Historia Regional?”, Historia Mexicana, abril-junio, vol. LI, N004, México D.F. El Colegio de México, pp. 867-897.

Nievas, F. 2009. "Sociología de la Guerra", Redes.com: Revista de estudios para el desarrollo social de la Comunicación. ISSN 1696-2079, №5, 2009, PP. 25-48.

Núñez, J. 2003. 1891: Crónica de la Guerra Civil, Santiago de Chile, LOM Ediciones.

Ortega, L. 2005. Chile en ruta al capitalismo, Cambio, Euforia y Depresión. Santiago, LOM ediciones, DIBAM; Centro de Investigaciones Barros Arana.

Pacheco, A. 2003. Economía y Sociedad de Concepción. Siglo XIX: sectores populares urbanos 1800 1885. Primera edición, Concepción, Universidad de Concepción, Facultad de Humanidades y Arte, Departamento de Ciencias Históricas y Sociales.

Pinto Rodríguez, J. \& Órdenes Delgado, M. 2012. Chile, una economía regional en el siglo XX. La Araucanía, 1900 - 1960. Osorno, Ediciones Universidad de La Frontera.

Pinto Rodríguez, J. 2015. Conflictos fronterizos en la Araucanía, siglos XIX y XX. Temuco, Ediciones Universidad de la Frontera.

Pinto, J. \& Valdivia, V. 2009. ¿Chilenos todos? La construcción social de la nación (1810-1840), Santiago de Chile, LOM ediciones.

Pizarro Soto, J. A. 1991. Lebu. De la Leufumapu a su centenario 1540-1962, Santiago, Editorial Ñielol S.A.

Ramírez Necochea, H. 2007. Obras escogidas. Balmaceda y la contrarrevolución de 1891. Historia del Movimiento Obrero en Chile. (1958) Volumen I, Santiago de Chile, LOM ediciones.

Robles Ortiz, C. 2009. "La producción agropecuaria chilena en la 'Era del Salitre' (1880-1930)", América Latina en la Historia Económica, número 32, julio-diciembre. Pp. 113-134.

Rodriguez Rautcher, S, 1986. Problemática del soldado durante la Guerra del Pacífico, Santiago, Colección Biblioteca Militar LXX-1, Edimpres Ltda.

Salazar, G. \& Pinto, J. 2002. Historia Contemporánea de Chile IV: Hombría y Feminidad, Santiago de Chile LOM ediciones.

Salazar, G. 2003. Historia de la acumulación capitalista en Chile, 1a ed., Santiago de Chile, LOM Ediciones.

Salazar, G. 2015. Labradores, Peones y Proletarios. Formación y crisis de la sociedad popular chilena del siglo XIX. Santiago de Chile, LOM ediciones (decimoséptima reimpresión).

San Francisco, A. 2006. "Historiografía y nuevas perspectivas sobre la Guerra Civil chilena de 1891", BICENTENARIO, Revista de Historia de Chile y América, Vol. 5, $\mathrm{n}^{\circ} 1$, Santiago de Chile, Centro de Estudios Bicentenario, pp. 85-125. 
Thompson I.A.A. 2003. "El soldado del Imperio. Una aproximación al perfil del Recluta español del siglo de oro." Manuscrits 21. Pp. 17-38.

Venegas, F. 2013. "Los sectores populares en la Guerra Civil de 1891: consecuencias de su desenlace en Placilla", en Ávalos H; Saunier, A; Delgado, A. \& Venegas, F. 2013. Bosque de La China: testimonio de un pasado sangriento. Batalla de Placilla - 1891. Valparaíso, Consejo Nacional de la Cultura y las Artes.

Vergara Quiroz, S. 1993. Historia Social del Ejército de Chile. Vol. I Ejército, sociedad y familia en los siglos XVIII y XIX. Santiago de Chile, Universidad de Chile, Dirección general Académica Estudiantil.

Verniory, G. 2001. Diez años en Araucanía, 1889-1899, Segunda edición, Santiago de Chile, Pehuén Editores.

Vitale, L. 1992. Interpretación marxista de la historia de Chile. Tomo V, Santiago de Chile, Ediciones Cela, Rucaray.

Weber, Max. 2001. La ética protestante y el espíritu del capitalismo, Barcelona, Ediciones Península. 